\title{
Early Postnatal Development of Vasoactive Intestinal Polypeptide- and Peptide Histidine Isoleucine-Immunoreactive Structures in the Cat Visual Cortex
}

\author{
PETRA WAHLE AND GUNDELA MEYER
}

Abt. Neurobiologie, Max-Planck-Institut für Biophysikalische Chemie, Am Fassberg, 3400 Göttingen, Federal Republic of Germany (P.W.); Departamento de Anatomia, Facultad des Medicina, Universidad de La Laguna, Tenerife, Spain (G.M.)

\begin{abstract}
The early postnatal development of neurons containing vasoactive intestinal polypeptide (VIP) and peptide histidine isoleucine (PHI) has been analyzed in visual areas 17 and 18 of cats aged from postnatal day (P) 0 to adulthood. Neuronal types are established mainly by axonal criteria. Both peptides occur in the same neuronal types and display the same postnatal chronology of appearance. Several cell types are transient, which means that they are present in the cortex only for a limited period of development. According to their chronology of appearance the VIP/PHI-immunoreactive (ir) cell types are grouped into three neuronal populations.

The first population comprises six cell types which appear early in postnatal life. The pseudohorsetail cells of layer I possess a vertically descending axon which initially gives rise to recurrent collaterals, then forms a bundle passing layers III to V, and finally, horizontal terminal fibers in layer VI. The neurons differentiate at $\mathrm{P} 4$ and disappear by degeneration around $\mathrm{P} 30$. The neurons with columnar dendritic fields of layers IV/V are characterized by a vertical arrangement of long dendrites ascending or descending parallel to each other, thus forming an up to $600 \mu \mathrm{m}$ long dendritic column. Their axons always descend and terminate in broad fields in layer VI. The neurons appear at $\mathrm{P} 7$ and are present until P 20. The multipolar neurons of layer VI occur in isolated positions and have broad axonal territories. The neurons differentiate at $\mathrm{P} 7$ and persist into adulthood. Bitufted to multipolar neurons of layers II/III have axons descending as a single fiber to layer VI, where they terminate. The neurons appear at P 12 and persist into adulthood. The four cell types described above issue a vertically oriented fiber architecture in layers II-V and a horizontal terminal plexus in layer VI which is dense during the second, third and fourth week. Concurrent with the disappearance of the two transient types the number of descending axonal bundles and the density of the layer VI plexus is reduced, but the latter is maintained during adulthood by the two persisting cell types.

Two further cell types belong to the first population: The transient bipolar cells of layers IV, V, and VI have long dendrites which extend through the entire cortical width. Their axons always descend, leave the gray matter, and apparently terminate in the upper white matter. The neurons differentiate concurrently with the pseudohorsetail cells at $\mathrm{P} 4$, are very frequent during the following weeks, and eventually disappear at $\mathrm{P} 30$. The persisting bipolar cells
\end{abstract}

\footnotetext{
Accepted November 7, 1988.

Address reprint requests to Petra Wahle, Abt. Neurobiologie, Max-PlanckInstitute für Biophysikalische Chemie, Am Fassberg, 3400 Göttingen, Federal Republic of Germany.
} 
of layers II/III and IV have shorter dendrites and issue a diffuse axon plexus which largely remains intralaminarly. The neurons are recognizable from $\mathrm{P} 12$ and persist, although in the adult cat cortex they are rare.

The second population comprises two cell types. The neurons with vertically descending main axon and horizontal collaterals of layers II/III and IV form diffuse axon plexuses by means of horizontal and oblique collaterals. They seem to terminate in the form of en passant boutons on pyramidal cell bodies. The neurons appear at $\mathrm{P} 18$ and persist into adulthood. The neurons of layer $I$ have broad dendritic fields and unconspicuous short axons which diffusely distribute in superficial layers. The cells are recognizable from P 25 onwards. The appearance of the second population initiates a change from the so far vertically organized architecture to a more diffuse innervation pattern. The change is complete when the transient innervation patterns have become superseded during the second postnatal month by the basket cells of layers II/III and IV, which constitute the third population. These neurons by far outnumber all other cell types and, until the end of the second month, fill these layers with a dense terminal plexus. Thereafter, the number of somata and the terminal density is reduced in layer IV, so that in adult animals most neurons and the densest plexus reside in layers II/III. The innervation now is less dense in layer IV and only loose in deeper cortical layers.

In summary, transient VIP- and PHI-ir cell types dominate the early postnatal cortex. They form a largely vertical fiber architecture, and degenerate and become eliminated by probably cell death around the end of the first month. Concurrently with their disappearance and during the second postnatal month, the persisting cell types form a completely different innervation pattern which reaches an adult state late postnatally.

Key words: transient neurons, classification of cell types, development of the innervation pattern, species differences, vasoactive intestinal polypeptide, and peptide histidine-isoleucine immunohistochemistry

Early studies on the development of cortical neurons described a process of continuous maturation leading to morphological and functional maturity with structures persisting into adulthood (Cragg, '75; Feldman and Dowd, '75; Lund et al., '77; Parnavelas et al., '78; Boothe et al., '79; Winfield, '81; Nieyer and Ferres-'Torres, '84). However, regressive events, such as loss of dendritic spines, axonal processes, and even elimination of a neuronal and synaptic overproduction are inherent to development (Hamburger and Oppenheim, '82; O'Kusky and Colonnier, '82; O'Kusky, '85; Oppenheim, '85). Cell death as well as morphological transformation are discussed as reasons for the disappearance of some cell types of the pre- and early postnatal cortex (Purpura et al., '60; Marin-Padilla, '72; Bradford et al., '77). However, recent reports have described neurons of the cortical subplate which are present only during limited periods of pre- and early postnatal life (Luskin and Shatz, '85a). They form morphologically defined cell types which are recognizable by their transmitter content and issue specific innervation patterns (Wolff et al., '84; Chun et al., '87; Wahle and Meyer, '87a,b; Wahle, '87; Wahle et al., '87). These subplate neurons degenerate and are eliminated by cell death (Kostovic and Rakic, '80; Wahle and Meyer, '87a; Valverde and Facal-Valverde '88), thus disappearing before adulthood. Furthermore, even neurons of persisting cell types derived from the cortical plate degenerate. For example, several perinatally appearing cholecystokinin-immunoreactive neuronal types undergo a certain turnover; the neurons appear with a marked heterochrony, and during the first postnatal weeks, immature, fully differentiated and degenerating cells of the same type are concurrently present (Wahle and Meyer, '87b; Meyer and Wahle, '88).

The present study describes the morphology, axonal patterns and postnatal development of visual cortical neurons immunoreactive (ir) for vasoactive intestinal polypeptide (VIP) and the recently discovered peptide histidine isoleucine (PHI) (Tatemoto and Mutt, '81; Said, '84; Tatemoto, '84). We have investigated both peptides because their molecular similarity (13 common amino acids), and the fact that they derive from a common precursor (Christofides et al., '82a; Fahrenkrug, '85; Fahrenkrug and Petersen, '86) suggests that both are colocalized in the same neuronal types. PHI has so far been studied only in the rodent brain (Christofides et al., '82b; Christofides et al., '83a; Hares and Foster, '88). VIP-ir neurons have been described in the developing and adult rodent and lagomorph brain, as nonpyramidal, mainly bipolar cells (Loren et al., '76; Emson et al., '79; McDonald et al., '82; Connor and Peters, '84; Morrison et al., '84; Cajal-Agüeras et al., '86). To date, nothing is known about the ontogeny of VIP- or PHI-ir neurons in the cat cortex. In the adult cat cortex, the two studies that have reported the morphology of VIP-ir neurons (Obata-Tsuto et al., '83; Peters et al., ' 87 ) have mainly described bipolar and modified bipolar cells, so that species differences between carnivores and rodents have not been detected. Furthermore, in these studies cells were classified solely by dendritic criteria and neither axonal ramifications nor innervation patterns were considered. We show here that different VIP- and PHI-ir cell types are present in the cortex, that they differentiate with a characteristic chronology, that 
three of these cell types are present only transiently, and that the VIP/PHI-ir innervation pattern of the early postnatal cortex is completely different from the adult innervation.

Finally, the chronology of the VIP-ir and PHI-ir structures is compared to that of neuropeptide $\mathrm{Y}$ - and cholecystokinin-ir cell types described in previous and parallel studies (Wahle and Meyer, '87a; Meyer and Wahle, '88), and hypothetically a circuit model is proposed which incorporates the most prominent axonal projection patterns of transient and persisting peptide-ir neurons. A preliminary report has been published in abstract form (Wahle and Meyer, '87b).

\section{MATERIALS AND METHODS}

Our material consists of kittens at the following age stages: 4 hours (2 animals), 12 hours (2), 24 hours after birth or postnatal day (P) 1 (2), P 2 (1), P 4 (2), P 5 (1), P 6 (2), P 7 (1), P 10 (2), P 11 (1), P 12 (3), P 14 (1), P 15 (1), P 16 (1), P 18 (2), P 20 (1), P 21 (1), P 23 (1), P 25 (2), P 26 (1), P 27 (1), $\mathrm{P}$ (29), P 30 (1), P 33 (1), P 35 (1), P 39 (1), P 48 (1), one 4-month-old, one 5-month-old, and four adult cats $(2-3 \mathrm{~kg}$ body weight). Most animals also provided data for previous studies (Wahle and Meyer, '87a; Wahle et al., '87; Meyer and Wahle, '88). Animals were perfused under deep anesthesia $\left(60 \mathrm{mg} / \mathrm{kg} \mathrm{Nembutal}{ }^{\circledR}\right)$. Perfusion, tissue processing and immunohistochemistry by use of the PAP method were carried out as previously described (Wahle and Meyer, '87a). The polyclonal rabbit antisera, one against vasoactive intestinal polypeptide, the other one against peptide histidine isoleucine (gift from Dr. J.M. Polak; for specification see Christofides et al., ' $83 \mathrm{~b}$; Bishop et al., '84) were used at a 1/700-1/ 800 dilution. Controls were carried out by omitting the primary antiserum, by substitution of the primary serum by normal rabbit serum diluted $1 / 1,000$, and by preabsorbing 1 ml diluted antiserum with $100 \mu \mathrm{g}$ VIP or PHI, respectively (VIP and PHI, porcine, synthetic, Sigma Chemical Co., St. Louis, MO). These procedures all abolish specific staining. Cross-blocking did not quench the specific staining, indicating that the anti-VIP-antiserum does not react with $\mathrm{PHI}$ and vice versa (Bishop et al., '84). Series of alternate sections stained with thionin and cytochrome oxidase (Wong-Riley, '79) served to identify cortical layers and the boundaries of area 17 and 18. Axon terminal portions were identified with the aid of a Nomarski optic system.

A total of 325 specifically and more-or-less completely stained VIP- and PHI-immunoreactive neurons were drawn from single histological sections with a camera lucida at a magnification of $\times 800$. The intracortical distribution of somata and terminals was plotted with an $\mathrm{X} / \mathrm{Y}$-plotter attached to a Leitz microscope.

\section{RESULTS}

For each of the two peptides, the cell types, their chronology of development, and the innervation patterns were analyzed separately. When the results were compared, we found no differences; the same cell types were present in both the PHI and the VIP series. They displayed the same morphological variety and the same postnatal chronology. In one $P$ 16 and one $P 27$ animal some alternate sections were stained with anti-VIP, anti-PHI, and with a mixture of both antisera. In sections incubated with the mixture of both antisera, the same cell types were observed and with the same frequency of occurrence. The double-staining procedure thus did not result in more cells per histological section than each single-staining procedure. We assume that the antisera recognize the same neurons. Therefore the cells are referred to as VIP/PHI-ir neurons.

We have grouped the VIP/PHI-ir cell types into three neuronal populations. Each neuronal population is defined in a chronological sense and composed of several cell types which display a similar time course of appearence by differentiation and/or disappearance by degeneration. Table 1 summarizes the time course of appearance, laminar positions, and characteristic morphological features of the cell types which comprise the populations. From the 325 camera lucida drawn VIP-ir and PHI-ir neurons, 207 belong to the first, 60 to the second, and 58 to the third population. VIP/ PHI immunohistochemistry reveals several stages of morphological differentiation and degeneration. The process of maturation and degeneration is the same as that described in detail for the neuropeptide Y-ir axonal loop cells (Wahle and Meyer, '87a) and cholecystokinin-immunoreactive (CCK-ir) multipolar neurons of layer VI (Meyer and Wahle, '88). This process will be described therefore only briefly for two examples of the present study: the pseudohorsetail cells and transient bipolar cells. The following description is organized into two main sections. We will first describe the morphology and chronology of each cell type, and second, the development of the innervation pattern.

\section{The morphology and chronology of VIP/PHI-ir cell types}

The first population. The first population is composed of six different cell types. Four types possess axons projecting to and terminating in layer VI: the pseudohorsetail cells and the neurons with columnar dendritic fields are only transiently present, while the multipolar neurons of layer VI and the bitufted to multipolar neurons of layers $I I / I I I$ persist into adulthood. Two further types are the transient bipolar cells, which project into the white matter, and the persisting bipolar cells, which have local axons.

TABLE 1. Neuronal Populations

\begin{tabular}{llll}
\hline Cell type & Mainly located in layers & Present from- & Characteristic features \\
\hline $\begin{array}{l}\text { First population } \\
\text { Pseudohorsetail }\end{array}$ & & & P 4-30 \\
Columnar dendritic field & I, II & P 7-20 & Axonal bundle to layer VI, collaterals in layer I \\
$\begin{array}{l}\text { Multipolar VI } \\
\text { Bitufted to multipolar III }\end{array}$ & IV,V & P 7-adult & Columnar dendritic fields, broad axon plexus, 2 axons \\
Transient bipolar & II, III & Proad axonal domains, 2 axons \\
$\begin{array}{l}\text { Persisting bipolar } \\
\text { Second population }\end{array}$ & IV, V, VI & P 4-30 & Single descending axon \\
$\begin{array}{l}\text { Vertical descending axon } \\
\text { Layer I }\end{array}$ & II, III, IV & P 12-adult & Shodially oriented dendrites, subplate projection \\
Third population & II, III & P 18-adult & Horizontal collaterals, variable dendritic trees \\
Local basket & I & P 25-adult & Few long dendrites, unconspicuous, small axon plexus \\
\hline
\end{tabular}




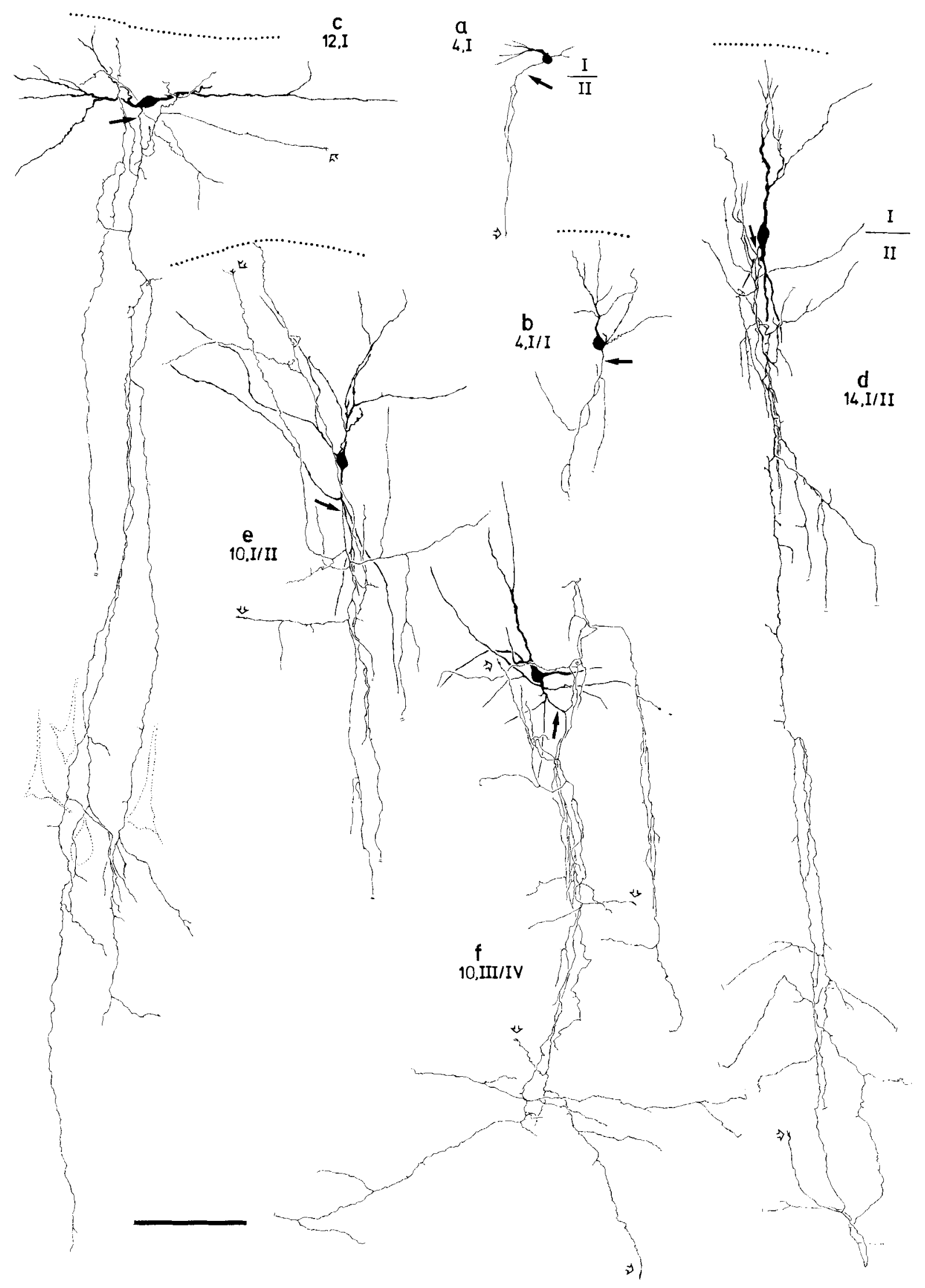

Fig. 1. Pseudohorsetail cells. a,b: Differentiating cells. c-f: Fully differentiated cells. Note the complete axonal pattern in c,d,f. Pyramids indicate layer $\mathrm{V}$ in $\mathrm{c}$. In e, the distal portion was not represented, because the fiber bundle has left the plane of the section. Compared with $d$ the axonal pattern of the neuron $f$ appears somewhat compressed. This is due to the neuron's position in deep layer III at the bottom of a sulcus, however, the complete axonal pattern is recognizable. The dotted line in b-e indicates the pial surface. VIP-ir neurons, a,b,d;

PHI-ir neurons, c,e,f. Scale: $100 \mu \mathrm{m}$. In this and the following figures the neurons are oriented with the pial surface on top. Age of the animal and position of the soma are indicated for the neurons shown in the camera lucida drawings; for example in Figure 1, cell e was found at P 10, and the cell body was located at the layer I/II border. Black arrows mark axons; open arrows mark growth cones; asterisks indicated perisomatically arranged terminal portions. 

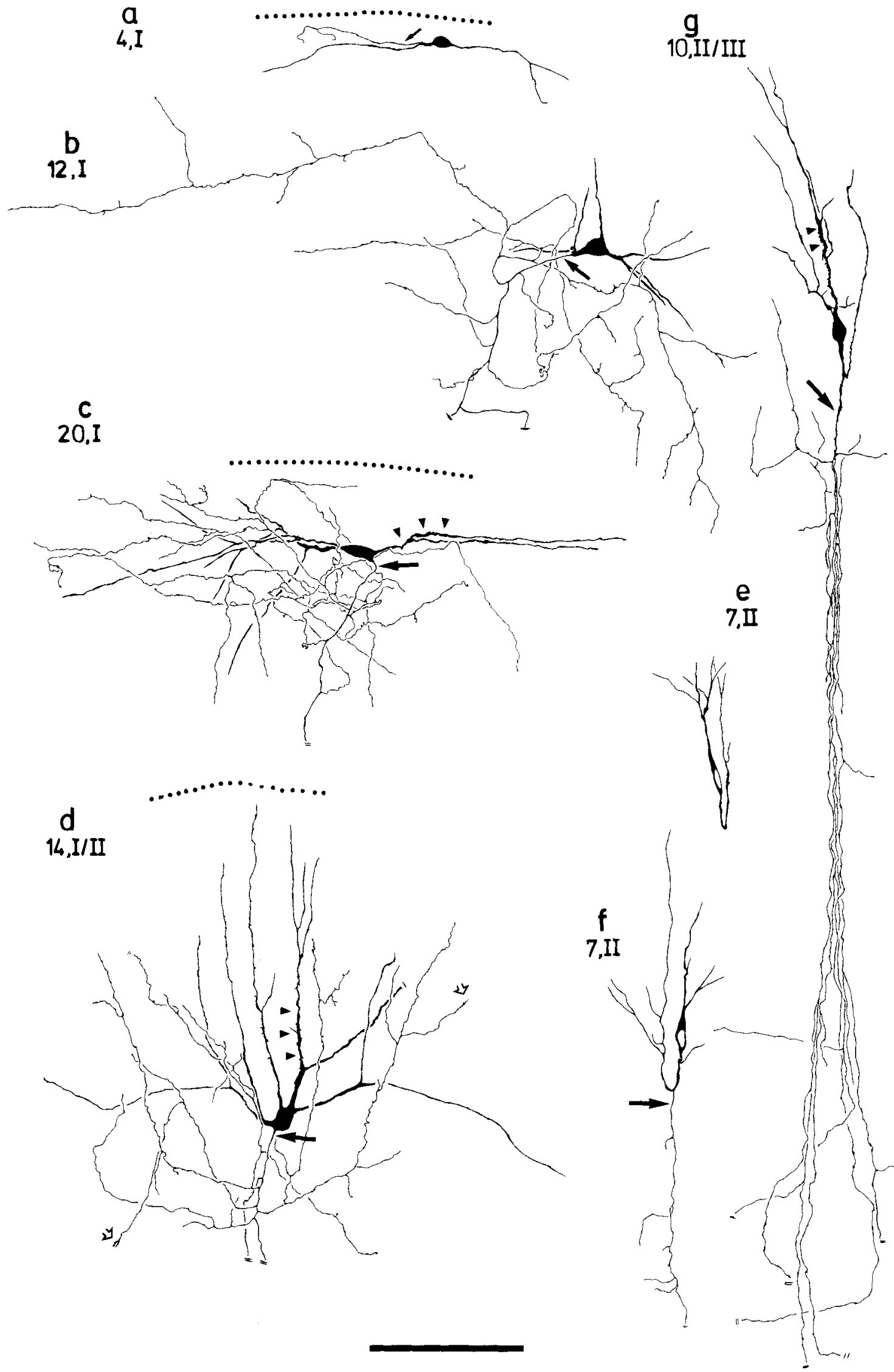

Fig. 2. Pseudohorsetail cells. a: Horizontally oriented differentiating cell. b-d: Fully differentiated cells. The proximal portions of the axon, the soma and the dendritic trees are represented to show the variation. The axonal bundles and the distal portions are similar to those shown in Figure 1c,d,f. e-g: An extreme variant of the pseudohorsetail cell type. These neurons have a hook-shaped basal dendrite, thus a very
10,IIIIII

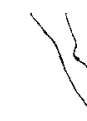

II

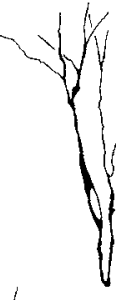

\section{e}
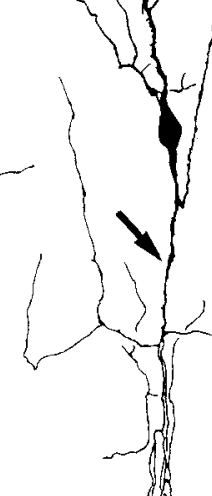

ע 
The characteristic feature of the pseudohorsetail cells (Figs. 1, 2, 4a-c) are their descending axonal bundles, which resemble those of the horsetail cells in the adult cat cortex. Most of these cells are located in layer $\mathrm{I}$, some are found in layer II, and fewer in layer III. In general, the fine, smooth and homogeneously stained axon emerges from the basal or lateral somatic pole and descends toward layer II. The descending axonal course can already be seen in immature neurons which have just started their morphological differentiation (Fig. 1a,b). The fully differentiated cells display a typical axonal morphology. In its proximal part, a number of recurrent collaterals originate which ascend obliquely or vertically to layer I (Figs. 1c,e, 2b-d; a photomontage is shown in Fig. 4c). Most remain in the vicinity of the dendritic tree, they rarely travel for longer distances (Fig. $2 \mathrm{~b}$ ). The degree of proximal ramification is variable, as shown in Figure $2 \mathrm{~b}-\mathrm{d}$. In some neurons the collaterals form a denser plexus within the dendritic tree (Fig. 2c); normally, however, the recurrent plexus is as loose as in Figure $2 \mathrm{~d}$. The collaterals remain smooth or fine beaded and in general do not develop prominent terminal varicosities.

The middle portion is characterized by the presence of the axonal bundle (Fig. 4a,b). Further collaterals emerge which no longer ascend into the dendritic domain, but descend as several parallel fibers (Fig. 1c,d,f) through layers III and IV (Figs. 4e, 7c). In general, the width of these axonal bundles is about $100 \mu \mathrm{m}$ (Fig. 1c,d). It may well be smaller; for example, neurons of an extreme variant of this cell type (Fig. $2 \mathrm{~g}$ ), which is rather bipolar in form, have a narrow axonal column of only about $20 \mu \mathrm{m}$ width.

The distal portion is represented by the preterminal and terminal plexus where the bundle enters layer VI (Fig. 4d). While passing through layer $\mathrm{V}$, the axonal bundle fans out (Fig. 2g) or issues additional collaterals. Their smooth profile changes to a more beaded appearance and they finally become varicose. In layer VI, the fibers eventually bend off into all directions and follow more-or-less horizontal courses (Fig. 1d,f). They do not descend beyond layer VI. Single collaterals can be followed for $500 \mu \mathrm{m}$ in a tangential plane; most, however, can be traced only for shorter distances because they terminate or leave the plane of the section. The fibers seem to form en passant boutons in close apposition to unstained somata (identified with Nomarski optics) and free in the neuropil.

The somata of fully differentiated pseudohorsetail cells are about $14-20 \mu \mathrm{m}$ in diameter. The dendrites of most cells are vertically bitufted (Fig. 4a,b), but multipolar forms (Figs. 1f, 2b,d) are observed as well. Horizontally bitufted cells occur only in the upper half of layer I (Figs. 1c, 2a,c). In general, apical tufts are denser; sometimes the basal "tuft" is represented only by one dendrite. Basal dendrites often bend upwards (Fig. 7i). In such cells the apical and basal dendrites together form a very narrow dendritic domain (Fig. 2g). This feature can already be recognized in undifferentiated (Fig. 2e, note that this immature cell has not yet developed an axon) and differentiating cells (Fig. 2f; the neuron has started axonal outgrowth).

Presumptive pseudohorsetail cells differentiate from $\mathrm{P} 4$ onwards in layer I. At this stage the somata are about $5 \mu \mathrm{m}$ in diameter and consist of just the nucleus and scant cytoplasm. The dendrites are short and poorly branched (Fig. 1a, 2a,e). The axons, led by growth cones, already descend into layers II/III. The collateral system has not yet formed. Fully differentiated forms can be identified from $\mathrm{P} 7$ onwards. During the following period, additional pseudo- horsetail cells differentiate, while others already display symptoms of degeneration. Degenerating cells display thick primary dendrites which are swollen by vacuoles (Fig. 7i) or are coarse and irregularly beaded. In a final stage, they have shrunken somata and dendrites show breaks or are twisted like corkscrews (Fig. 7h). Degenerating cells are very intensely labeled. The pseudohorsetail cell type is present until $\mathrm{P} 27 / 30$, at which time most representatives are degenerating. The type is no longer present in the fifth week.

The second VIP/PHI-ir cell type in the first population are the neurons with columnar dendritic fields of layers IV and $\mathrm{V}$ (Figs. 3, 4f). In general, axons emerge from the lower somatic pole (Fig. 3c,d) and always descends to layer VI. On their course the main fiber branches into a wide plexus (Fig. 3c), which may well extend for $1 \mathrm{~mm}$. The collaterals remain in layer VI and progressively develop a more beaded appearance. They terminate in boutons which seem to contact somata in en passant manner; some short collaterals also bend around immunonegative somata. Some neurons with columnar dendritic fields issue two axons. The distance between the two axonal origins is variable, axons may emerge close to each other from the same somatic site (Fig. $3 \mathrm{c}$ ), from more distant somatic sites (Fig. 3b), or even from opposite somatic poles (not shown). Double axons always behave like single ones, they grow out concurrently and are equally well developed: their course, branching and terminal pattern are similar, and they form a common axonal field.

The somata of fully differentiated neurons with columnar dendritic fields are about $20 \mu \mathrm{m}$ in diameter. Their bitufted to multipolar dendritic trees display a conspicuous configuration: ascending or descending primary and secondary dendrites are arranged parallel to each other. They thus form a vertically oriented columnar dendritic field of about $100-150 \mu \mathrm{m}$ in diameter which extends vertically up to 600 $\mu \mathrm{m}$ (Fig. 3c). Only in differentiating neurons of this type the vertical extent of the dendritic field is smaller (Fig. 3a). Some secondary dendrites arise at right angles from short, horizontally oriented primary ones. The latter often end in a T-shaped branch point (thick black arrows in Figs. 3c, 4f). Many dendrites are fine, lightly, and homogeneousiy stained.

The first VIP/PHI-ir neurons with columnar dendritic fields appear, lightly stained and less well differentiated, at P 7 in layer V (Fig. 3a). From P 10 to P 18 well-differentiated neurons are observed, the axons of which contribute to the plexus in layer VI. Last representatives of this type were seen in $\mathrm{P} 20$ material.

A third type, the multipolar neurons of layer VI, represents a further component of the first population (Figs. 5, $13 f, g)$. These neurons have round to triangular somata of up to $20 \mu \mathrm{m}$ diameter, and most are located in upper layer VI or even at the border to layer V (Fig. 5d). The dendrites are often long, and apical dendrites may reach layer IV. The axon normally emerges from the basal cell pole, descends for a short distance (Figs. 5a,d, 13f) and then branch into a number of collaterals which form a loose plexus over the whole layer. Some multipolar neurons of layer VI may possess two axons, as documented in Figure 5a,b,e, and both have a similar form. The axon plexuses are at least coextensive with the dendritic fields; most extend beyond in a symmetrical fashion (Fig. 5a,d). The multipolar neurons of layer VI are not very numerous in our VIP/PHI material and are often separated by more than $1 \mathrm{~mm}$ cortical dis. tance. Their axons occupy independent territories. Neurons in isolated positions have symmetric axonal fields, for exam.- 


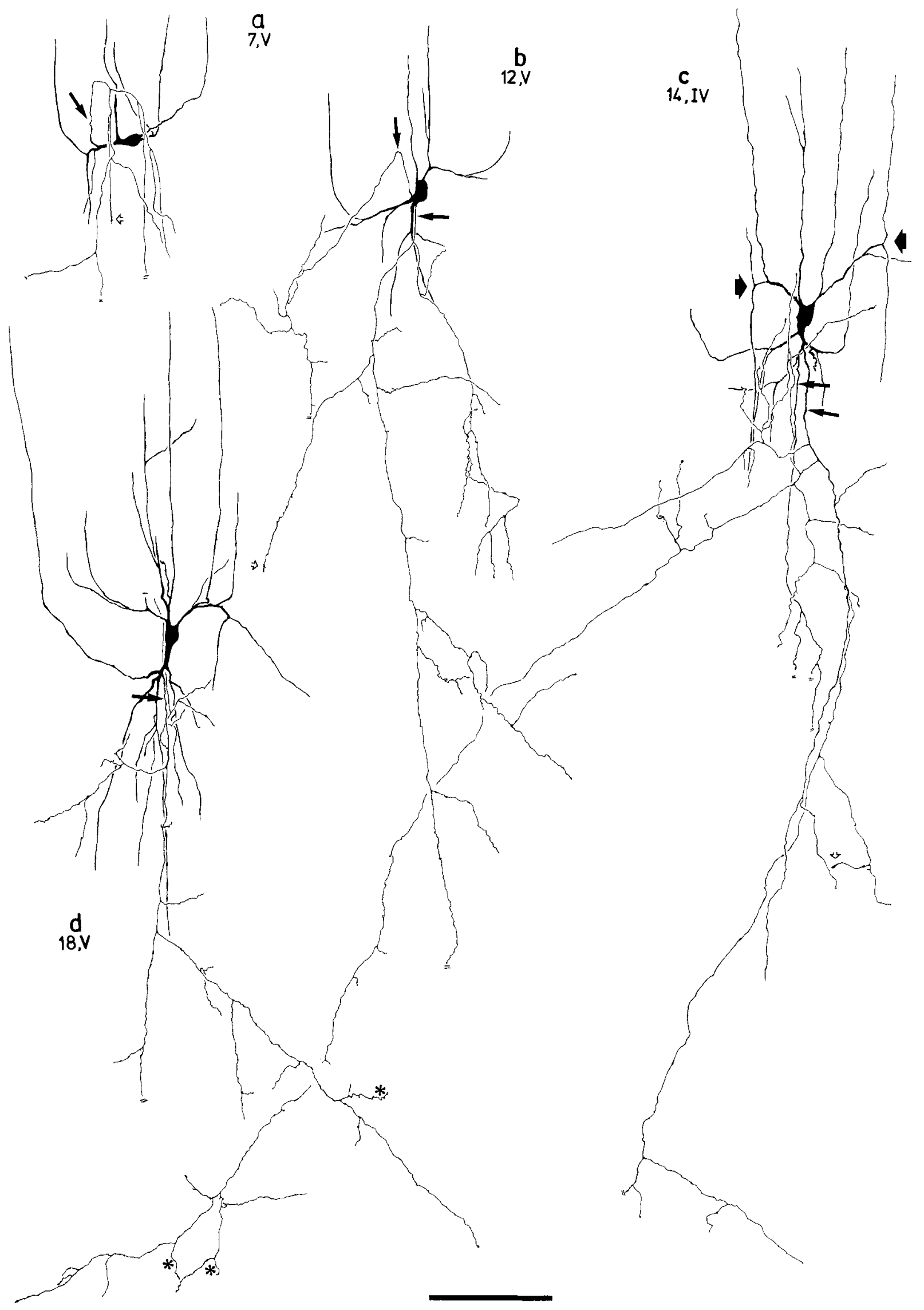

Fig. 3. Neurons with columnar dendritic fields of layers IV and V. Note the vertical arrangement of the dendritic trees, the thick black

arrows in $\mathbf{c}$ mark T-shaped dendritic branch points. Neurons b,c have two axons. VIP-ir neurons, b,d; PHI-ir neurons, a,c. Scale: $100 \mu \mathrm{m}$. 

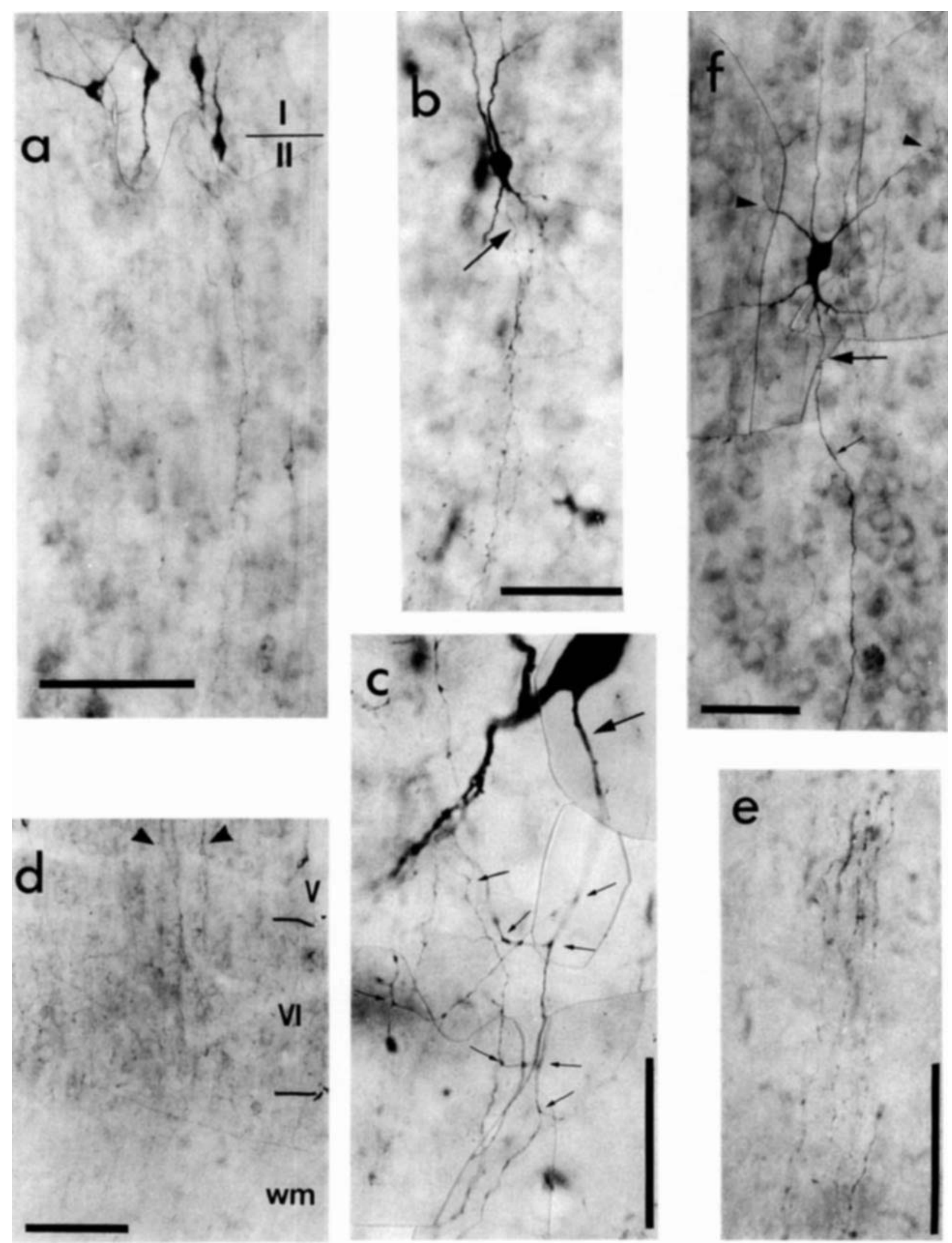

Fig. 4. Pseudohorsetail cells. a: Neurons are located in layer I and at the border to layer II (indicated). b: The axon descends and forms a bundle. c: High-power photomontage of a proximal axonal ramification, the fine arrows mark the branch points. Note that some collaterals ascend, while others descend. $\mathrm{d}$ : Two fiber bundles (arrowheads) reach

layer VI (indicated). Note the diffuse innervation of layer VI. e: High magnification of an axonal bundle as it passes layer IV. f: Neuron with columnar dendritic field; arrowheads mark T-shaped dendritic branch points, the fine arrow an axonal branch point. VIP-ir neurons, a,b; PHIir neurons: c-f. Scale: $100 \mu \mathrm{m}$ in a,d; $50 \mu \mathrm{m}$ in b,c,e,f. 

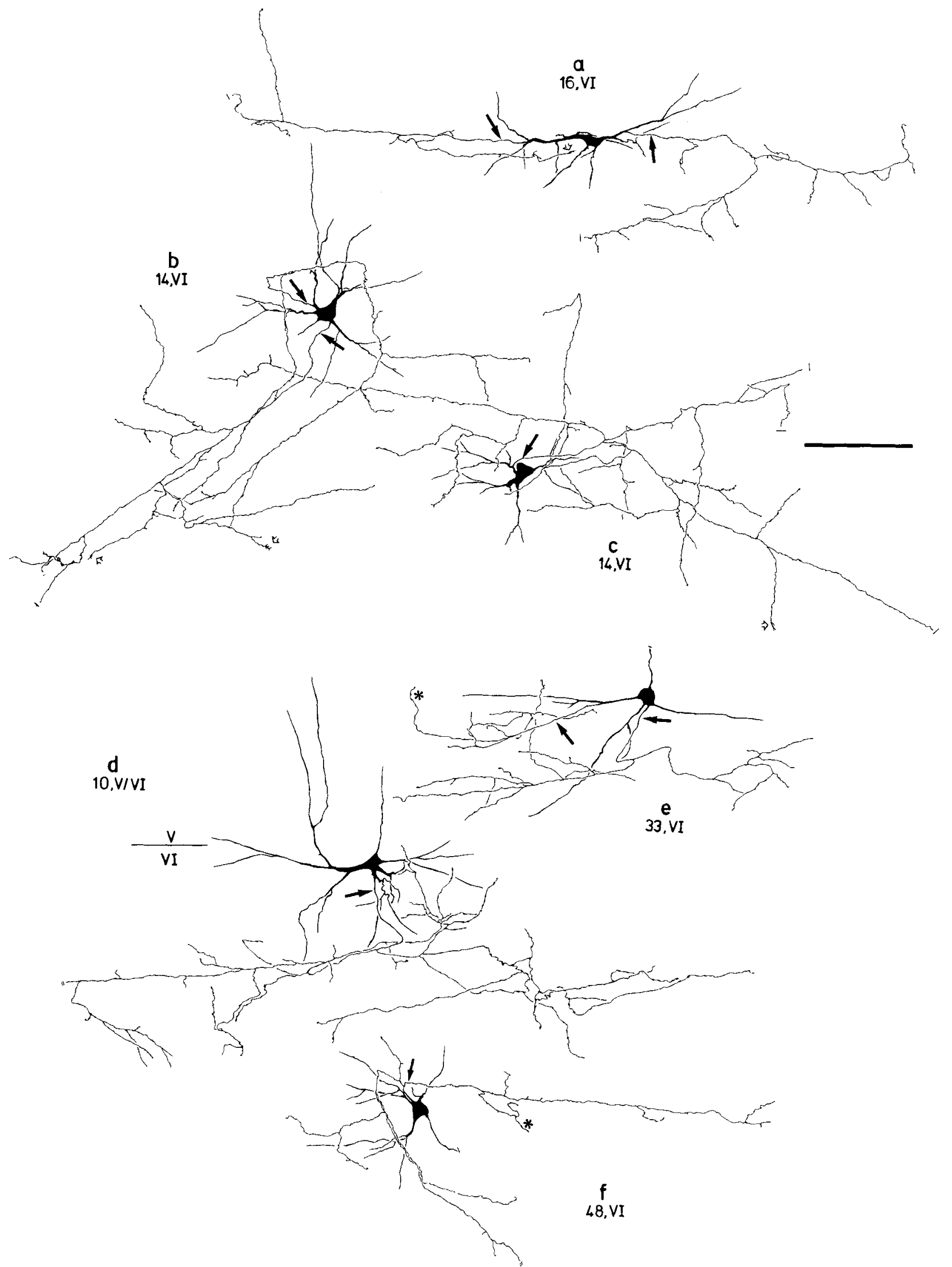

Fig. 5. Multipolar neurons of layer VI. b,c: The two neurons are drawn in their original position; note that the axonal domain of cell b bends to the right side, while that of cell $\mathbf{c}$ extends to the left. Neurons $\mathbf{a}, \mathbf{b}, \mathbf{e}$ have two axons. The layer V/VI border is indicated in $\mathbf{d}$. VIP-ir neurons, a,d,e; PHI-ir neurons, b,c,f. Scale: $100 \mu \mathrm{m}$. 


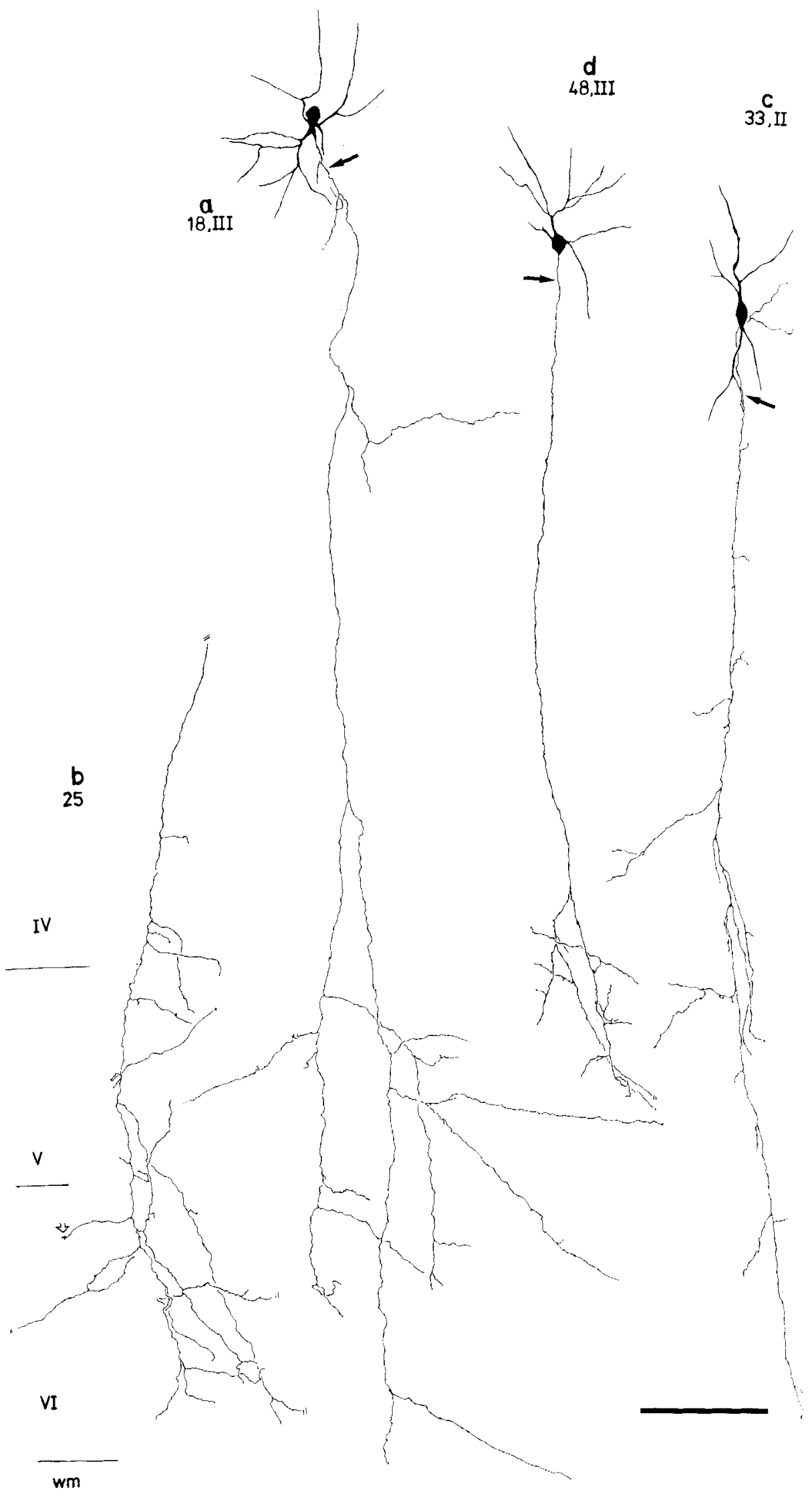

Fig. 6. Bitufted to multipolar neurons of layers II/III. Note that the axon descends as single fiber. b: Layers IV to VI are indicated. VIP-ir neurons: b,c; PHI-ir neurons: a,d. Scale: $100 \mu \mathrm{m}$. 

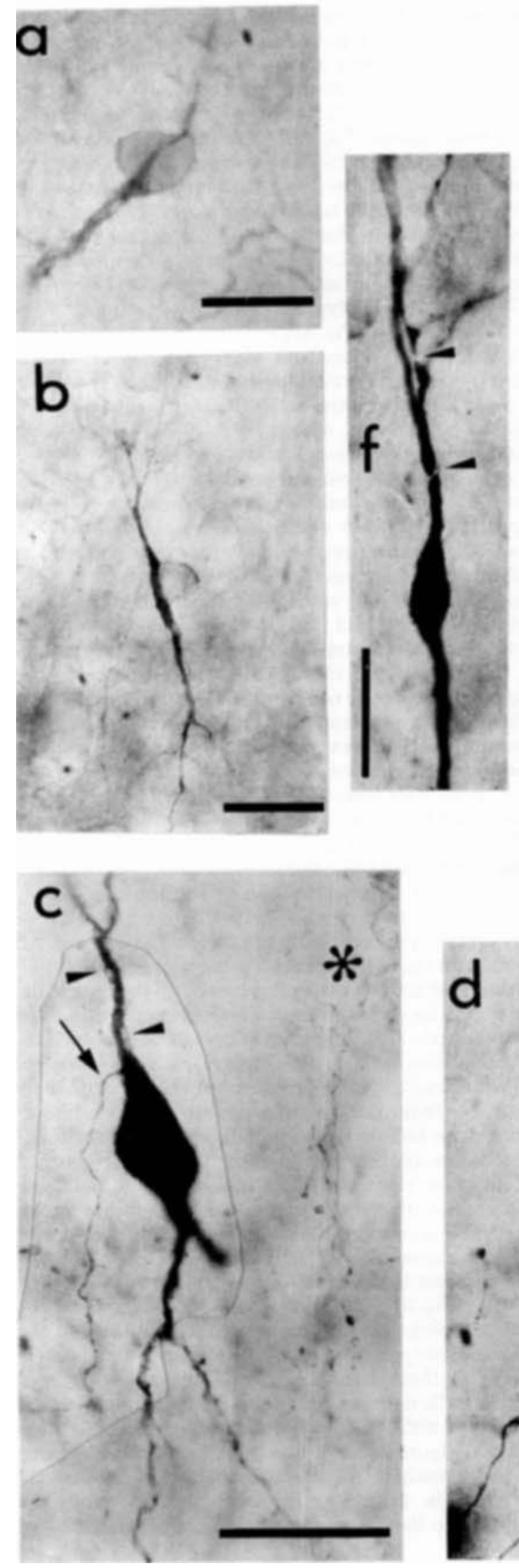
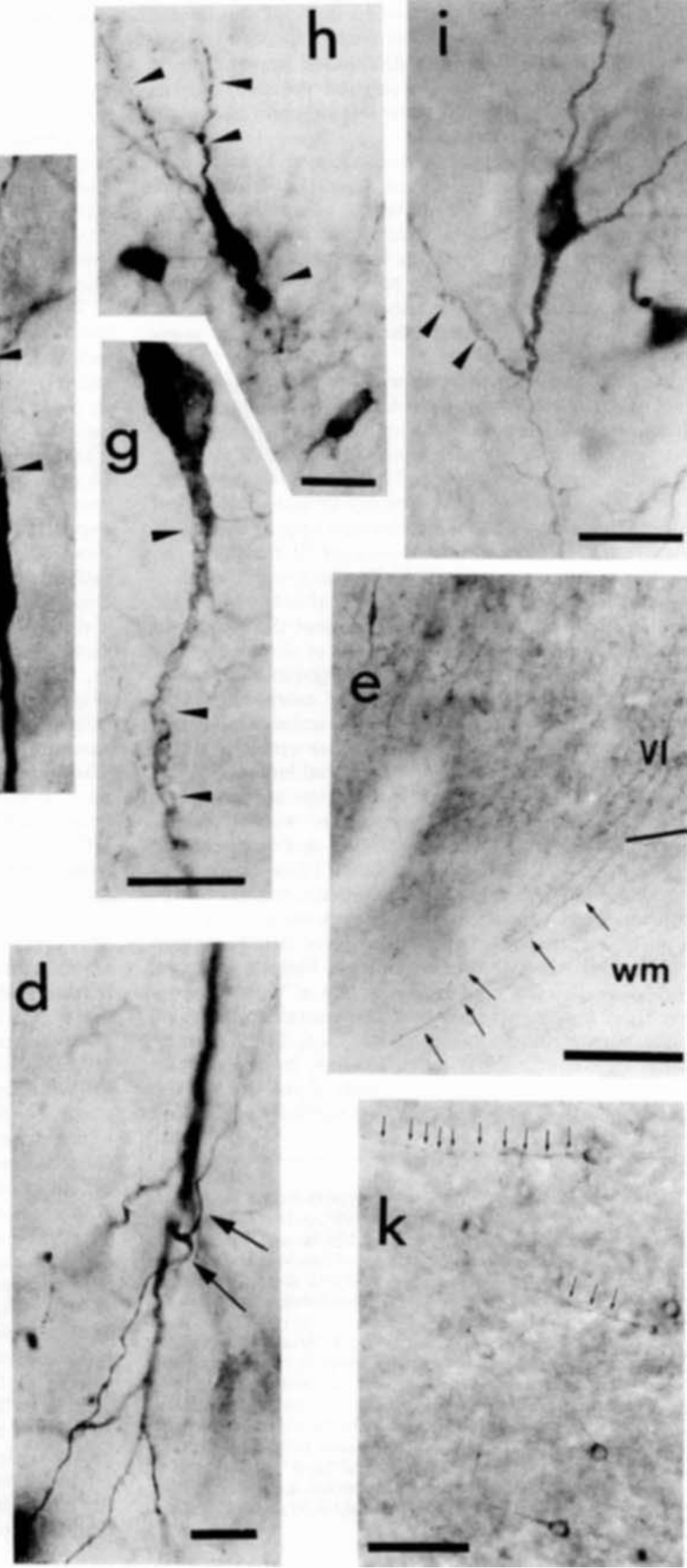
ple, in Figure 5a, where the two axons ramify into opposite directions extending along the medial flank of the lateral gyrus. In those rare cases where two neurons lie close to each other their axons go in opposite directions: An example is shown in Figure 5b,c (drawn in original position), where both axons of neuron $B$ bend to the left side and the single axon of neuron $C$ to the right side.

Differentiating multipolar neurons of layer VI appear at P 7; well-differentiated ones are observed from $P 10$ onwards. Their axons contribute to the plexus in layer VI (Fig. 13h) and they cannot be distinguished from axons of other types that terminate in this layer. Although the cell type persists into adulthood, we have found degenerating individuals concurrently with others being in an earlier stage of morphological differentiation during the first postnatal month.

During the second postnatal week a fourth type, the bitufted to multipolar neurons of layers II/III appear (Fig. 6 ). These neurons have about $20-\mu \mathrm{m}$ large somata and give rise to a descending axon which passes layers III/IV as single fiber. On its course a few short collaterals may emerge (Fig. $6 \mathrm{~b}, \mathrm{c})$, which neither ascend recurrently to layer I nor form axonal bundles. Longer beaded collaterals appear in layer $\mathrm{V}$ (Fig. 6a,b) and the fibers terminate in layer VI, mainly in the form of en passant boutons. In layer VI, the axonal morphology cannot be distinguished from axons of other cell types terminating here. We have not observed that the collaterals reach the same horizontal axonal extent of the multipolar layer VI neurons. The bitufted to multipolar neurons of layers $I I / I I I$ persist with an unchanged morphology into adulthood. In older kittens and adult animals they are largely outnumbered by neurons with other axonal patterns which by that time are present in superficial layers.

The last members of the first population are two types of bipolar cells. In the following section we will briefly demonstrate the stages of differentiation and degeneration displayed by VIP/PHI-ir bipolar cells. 'They can be unequivocally identified even at a very immature stage of differentiation (Figs. $7 \mathrm{a}, \mathrm{b}, 9 \mathrm{a}, \mathrm{b}$ ) when they possess just a $5-\mu \mathrm{m}$ small nucleus surrounded by a thin rim of lightly stained cytoplasm, and when they have not yet formed an axon. Characteristically, the nucleus looks like a "bubble" protruding from a primary process which contains almost all the immunoreactive cytoplasm (Figs. 7a,b, 9b). In many immature cells the "bubble" is visible only by the aid of a phase contrast optics, because it consists of just the nucleus and outer cell membrane but contains virtually no labeled

Fig. 7. a,b: Immature bipolar cells. b: Note the excentric position of the nucleus. a: The same feature just "rotated" $90^{\circ}$, so that the primary process crosses the nucleus. c: Differentiated bipolar cell. The arrowheads point to vacuolar inclusions in the proximal dendrite; the asterisk marks an axonal bundle of a pseudo-horsetail cell. d: Differentiated bipolar cell, the axon divides into two fibers immediately after the axon hillock. e: Axons of bipolar cells project into the upper white matter. The layer VI/white matter border is indicated. $f$ : Breaks in a bipolar cell's apical dendrite (arrowheads). g: Basal dendrite of a bipolar cell filled with vacuoles. i: Vacuolar inclusions in the basal dendrite of a pseudo-horsetail cell. h: Degenerating pseudohorsetail cell. Primary dendrites are swollen, the soma has shrunken, the basal dendritic stump is twisted, apical dendrites are broken (arrowheads). k: Immunoreactive cell bodies in the upper white matter at postnatal day 5 . The fine arrows mark some of the varicose processes. VIP-ir neurons, a,d,e,f,i,k; PHI-ir neurons, b,c,g,h. Scale: $10 \mu \mathrm{m}$ in $\mathrm{a} ; 20 \mu \mathrm{m}$ in b,c,d,f-i; $50 \mu \mathrm{m}$ in k; $100 \mu \mathrm{m}$ in $\mathrm{e}$. cytoplasm. The primary process seems to elongate and to develop into the apical or basal dendrite, respectively, and the neurons send out an axon. In Figure 9c, both dendritic and axonal tips bear growth cones. In more differentiated bipolar cells the nucleus is centered between the dendrites and surrounded by more cytoplasm. Degenerating bipolar cells have coarse (Fig. 8h), sometimes varicose dendrites, and show vacuolar inclusions in the somata and proximal parts of the dendrites (Fig. 7c,g). Irregular soma forms also appear, possibly due to soma shrinkage. The staining intensity increases and finally masks all organelles. The finer dendrites may adopt a tortuous course, but the long, major ones remain straight and may show breaks (Figs. 7f, $8 \mathrm{~h}$ ).

Two bipolar cell types can be distinguished. The transient bipolar cells (Fig. 8) are the most common VIP/PHI-ir cell type in the immature cat cortex. Most neurons are located in deeper cortical layers IV, V, and VI; only a few lie in layer III and in the white matter. Fully differentiated neurons have small, elongated $8-14-\mu \mathrm{m}$-diameter somata. The characteristic features are one (Fig. 8a) to two (Fig. $8 b, g)$ quite stout apical and basal dendrites, which ascend or descend vertically and may extend over the entire cortical depth (Fig. 8a,f). In addition, a variable number of finer dendrites are arranged obliquely, sometimes resulting in a rather bitufted appearance of the cell. The dendrites rarely branch further; only some of the long dendrites form small distal tufts (Fig. 8a). The axonal configuration is highly variable: the axon may emerge from any somatic pole (Figs. $7 \mathrm{c}, 8 \mathrm{a}, \mathrm{b}, \mathrm{d}$ ) or from the apical (Fig. 8c) or basal dendrite (Figs. 7d, 8g). In one cell (Fig. 7d) we found that a first axon collateral emerges unusually close to the axonal origin. The axons of the transient bipolar cells are fine and smooth. They descend and branch into a variable number of collaterals. The axonal plexus may consist of few fibers (Fig. $8 \mathrm{~b}, \mathrm{~g}$ ) or of a descending fiber bundle (Fig. 8a,c). Occasionally, some cells in layers V/VI may form a denser local plexus (Fig. 8d) from which some collaterals descend further. Although such local portions may contribute to the innervation of these layers, the main projection target of the transient bipolar cells is the superficial white matter. As can be seen in Figure $8 \mathrm{a}, \mathrm{f}, \mathrm{h}$, fibers pass the border between layer VI and the white matter, and growth cones indicate that they are still growing. Figure 8e shows an axon which branches as it enters the white matter. At the apex of a gyrus fibers enter the white matter vertically (Fig. 8h). Figure 7 e shows fibers entering the white matter more obliquely at the flank of the lateral gyrus. In distal portions the fibers develop a fine beaded appearance but no prominent terminal varicosities. Their termination pattern in the superficial white matter is unconspicuous, since the fibers end in only a fine knob. The Nomarski optic system did not reveal a possible target of the axon. The deep white matter, optic radiation, and corpus callosum are void of VIP/PHI-ir fibers.

In contrast to transient bipolar cells, the persisting bipolar cells (Fig. 9) have larger somata of 12-16 $\mu \mathrm{m}$ in diameter and are mainly localized in layers II, III, and IV. The proximal dendritic pattern of fully differentiated neurons is quite similar to that of the transient form, although persisting bipolar cells do not display the striking long dendrites. An important difference between the two types is the axonal pattern. Figure 9 shows that most axons of persisting bipolar cells remain intralaminar or within the limits of the dendritic fields (Fig. 9a,d,f,h). The plexus rarely extends beyond the dendritic domain (Fig. $9 \mathrm{~g}$ ) and fibers do not 


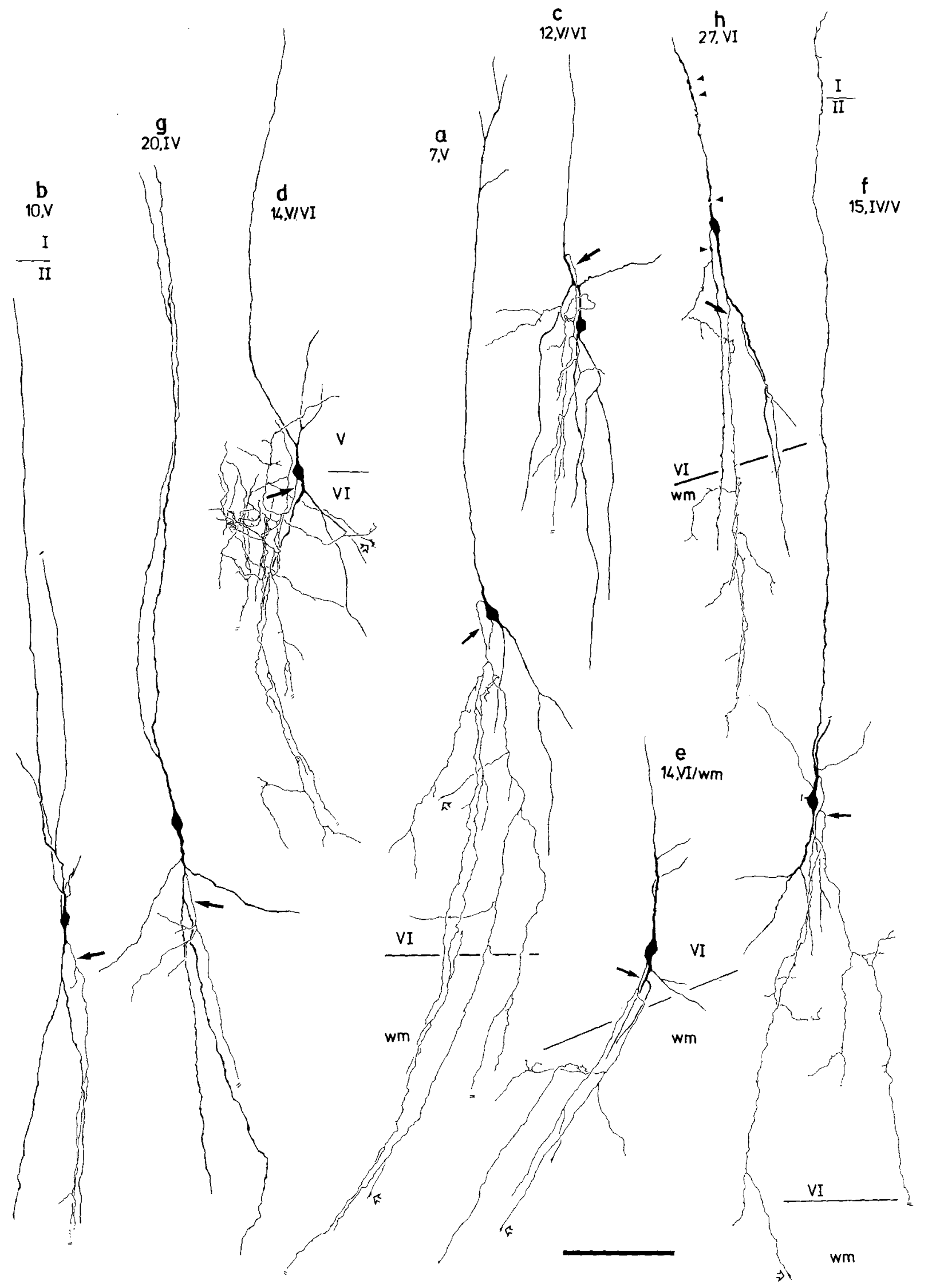

Fig. 8. Transient bipolar cells. Note the long dendrites, and axons projecting into the white matter. The layer VI/white matter border is indicated in $a, d-f, h$; the layer I/II border in b,f. The arrowheads in $h$

mark signs of degeneration. VIP-ir neurons, b,c,g,h; PHI-ir neurons, a,d,e,f. Scale: $100 \mu \mathrm{m}$. 


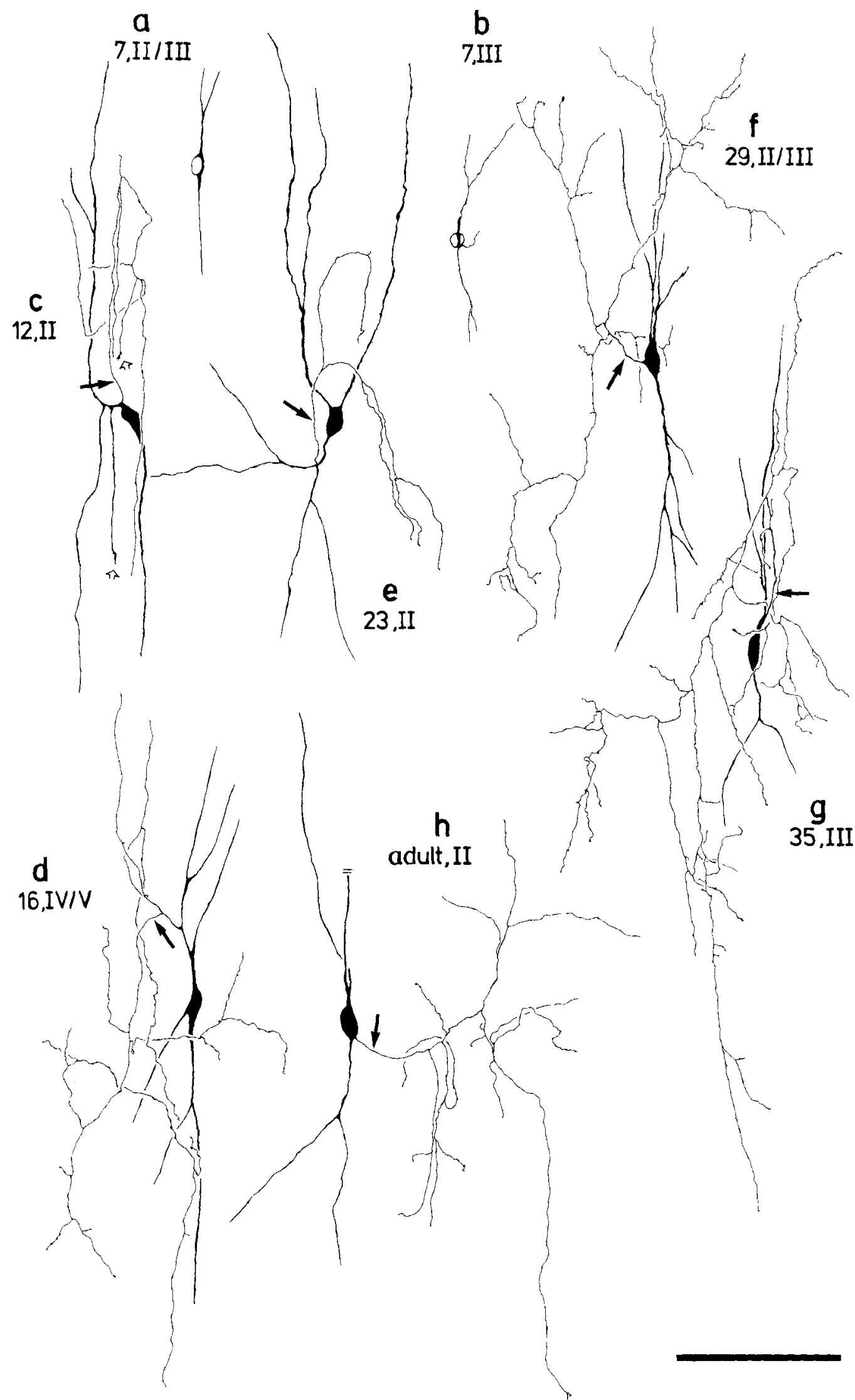

Fig. 9. Persisting bipolar cells. a, b: Immature bipolar cells, possibly belonging to the persisting bipolar cell type due to their position in superficial layers. c: Differentiating bipolar cell, the axon and one of the 
descend into the white matter. The axons are fine and smooth, and their ramification is rather diffuse. Prominent terminal varicosities and a projection target of persisting bipolar cells could not be identified.

Apart from the morphological and laminar differences between transient and persisting bipolar cells, they also differ in their postnatal chronology. Transient bipolar cells appear at $\mathrm{P} 4$, concurrent with the pseudohorsetail cells. Their numbers increase during the following week and stabilize in the third week. Thereafter neurons seem progressively to disappear (a neuron with a disintegrating dendrite is shown in Fig. 8b) and are not observed after the first postnatal month. As was the case with the pseudohorsetail cells, we found that the neurons of the transient bipolar cell type differentiate at different postnatal ages; and at all ages examined some individuals displayed signs of degeneration. In contrast, putative persisting bipolar cells appear at the beginning of the second week (Fig. 9a,b) in superficial layers. More differentiated forms (which now are classifiable because they have formed an axon plexus) are seen after P 12 (Fig. 9c). In the adult cortex VIP/PHI-ir persisting bipolar cells are not very frequently observed.

A VIP/PHI-ir cell group, positioned in the superficial white matter, is only briefly mentioned here (Fig. 7k). These cells are not classifiable because their processes could neither be identified as axons nor as dendrites. We have seen them only in kittens at $\mathrm{P} 4$ and $\mathrm{P} 5$, therefore we describe them together with the cell types of the first population. Their round somata of about $15 \mu \mathrm{m}$ diameter consist of a pale nucleus surrounded by moderately labeled cytoplasma. One or two processes which emerge from the cell bodies are up to $4 \mu \mathrm{m}$ thick and regularly beaded. They may extend for about $100 \mu \mathrm{m}$ and do not branch further. The processes have no preferred orientation.

The second population. The second population is composed of two cell types. Examples of the first type, the neurons with vertically descending main axon and horizontal collaterals, are shown in Figure 10. The somata are about $15 \mu \mathrm{m}$ in diameter and are located mainly in superficial layers II/III. Occasionally they may occur in layers IV/V (Fig. 10a). They have a variable dendritic configuration. Many are bitufted (Fig. 10b,c,d), others are multipolar (Fig. 10a,g), modified bipolar (Fig. 10f), or bipolar (Fig. 10e, compare this cell to Fig. 9 h: both cells would belong to a bipolar type by a purely dendritic classification, but they possess completely different axonal patterns). Longer dendrites and/or more profuse tufts extend towards the pial surface and dendrites sometimes reach as far as layer $I$.

The axonal domain is separated from the dendritic field. The axon emerges from the lower cell pole. The main fiber descends (Fig. 10f,e) through two or three layers before terminating or leaving the plane of the section. Most of the axon plexus is usually confined to layers II/III/IV; only axons of the occasional cells which are located deeper in the cortex extend into layers V/VI (Fig. 10a). At fairly regular intervals fine, beaded collaterals emerge perpendicular to the main axon (Fig. 10a,e,f). In general, they follow a horizontal or oblique course, and may extend for about $400 \mu \mathrm{m}$ (Fig. 10e). The plexus may be quite profuse (Fig. 10c). The varicosities of the beaded collaterals come in close apposition to round and triangular cell bodies (possibly pyramidal cells as identified by Nomarski optics) and issue a few boutons on somata or proximal dendrites, but are not observed to bend around target cells. Neurons of this type were first seen at $\mathrm{P} 18$, and their numbers increase during the follow- ing week. Their axons produce a rather diffuse innervation adding horizontal and oblique processes to the earlier, vertically organized pattern characteristic for the first population.

A second cell type is present in kittens aged 25 days and older: the neurons in layer $I$ and at the border to layer II (Fig. 11) have somata of variable diameter ranging from 14 to $22 \mu \mathrm{m}$. The dendritic configuration is multipolar or horizontally bitufted and the dendrites are confined to layer I. These neurons have few, often long, slightly beaded dendrites; sometimes the dendritic fields are as large as $500 \mu \mathrm{m}$ in diameter (Fig. 11b). Dendrites often end close to the pial surface (Fig. 11c,d). In contrast to the wide dendritic field is the fine, unconspicuous axon which always descends as a single fiber into layer II. Both, dense (Fig. 11d) and diffusely organized (Fig. 11a) plexuses are observed. Often the destination of the descending fiber could not be determined. The axons of the VIP/PHI-ir neurons of layer I neither issue a recurrent axon plexus nor form axonal bundles. So, by axonal criteria the neurons of layer 1 , which persist into adulthood, can be distinguished from the transient pseudohorsetail cells of the same layer. The fiber density in layer I of the late postnatal and adult animal is low and inhomogeneous. Some beaded plexuses of layer II basket cells may extend into layer I. Some fibers are found that run for longer distances, but their origin could not be determined.

We also saw a number of neurons during the third, fourth, and fifth postnatal week, which have the chronology of the second population, but which we could not classify into one of the above-mentioned groups. Most are located in layers III/IV/V. We observed multipolar neurons of about $20 \mu \mathrm{m}$ soma diameter in layers III and IV, the axons of which form ascending and/or descending plexuses. Some multipolar neurons had conspicuously long ascending or descending dendrites. Other neurons had horizontally oriented somata and axons. From all these variants we found too few cells and their axonal patterns were too heterogeneous to establish additional cell types. In older animals and in the adult, these variants are not longer observed, and layers IV and V especially are largely devoid of immunoreactive somata (Fig. 16).

The third population. The third population consists entirely of basket neurons (Figs. 12, 13a,b,c,e). Their somata are small and round with diameters of 10-15 $\mu \mathrm{m}$. Most cells are multipolar; often the dendrites cannot be followed for longer distances because the staining fades out. The fine axon arises from the soma or more rarely from a dendrite. After an initial segment of $30-50 \mu \mathrm{m}$ it branches into a dense plexus which may ascend (Fig. 12e,i) or descend (Fig. $12 \mathrm{~b}, \mathrm{f}, \mathrm{m})$. Some neurons possess axonal bundles which descend for at most two cortical layers (Fig. 12g). Others send out two axons which form one common field (Fig. 121). All collaterals are regularly beaded and exhibit prominent varicosities (Fig. 13b). These may form both en passant boutons and perisomatically arranged baskets (indicated by asterisks in Fig. 12m). The baskets enclose small pyramidal cell bodies of the superficial layers (Fig. 13b). The VIP/PHI-ir basket may be also formed by en passant boutons (Fig. 13c): up to four fibers (which may be collaterals of the same axon) converge upon one target cell, which may receive up to 15 boutons on its soma and proximal dendrites.

The basket neurons appear during the fourth and fifth week, mainly in layers III and IV. One neuron which probably belongs to the third population is shown in a still undifferentiated stage in Figure 13d (asterisk) in close proximity 


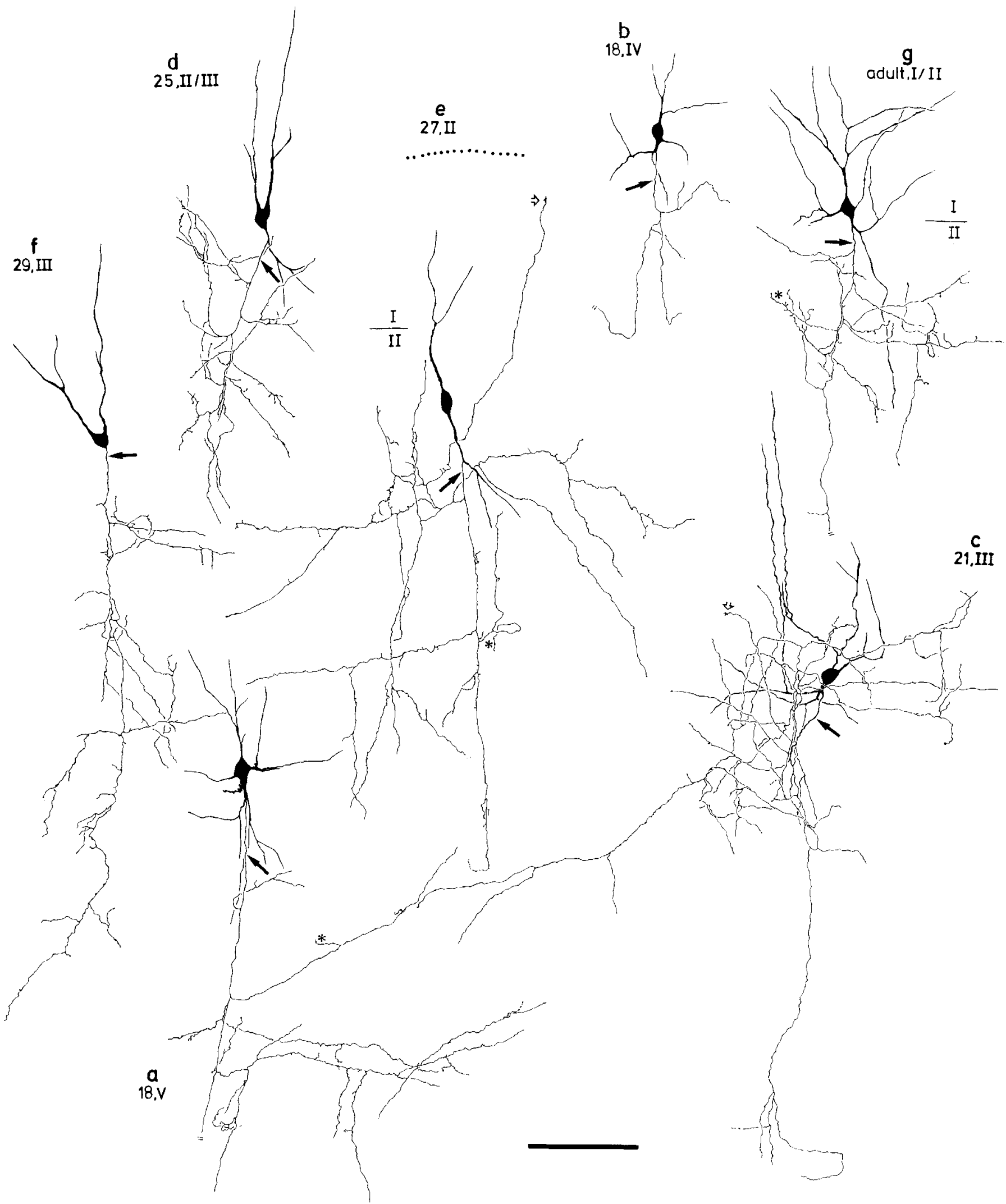

Fig. 10. Neurons of the second population with vertically descending main axon and horizontal collaterals. Note the variability of the dendritic configuration. The dotted line in e marks the pial surface; the

layer I/II border is indicated in e,g. VIP-ir neurons, b,d,e; PHI-ir neurons, a,c,f,g. Scale: $100 \mu \mathrm{m}$. 


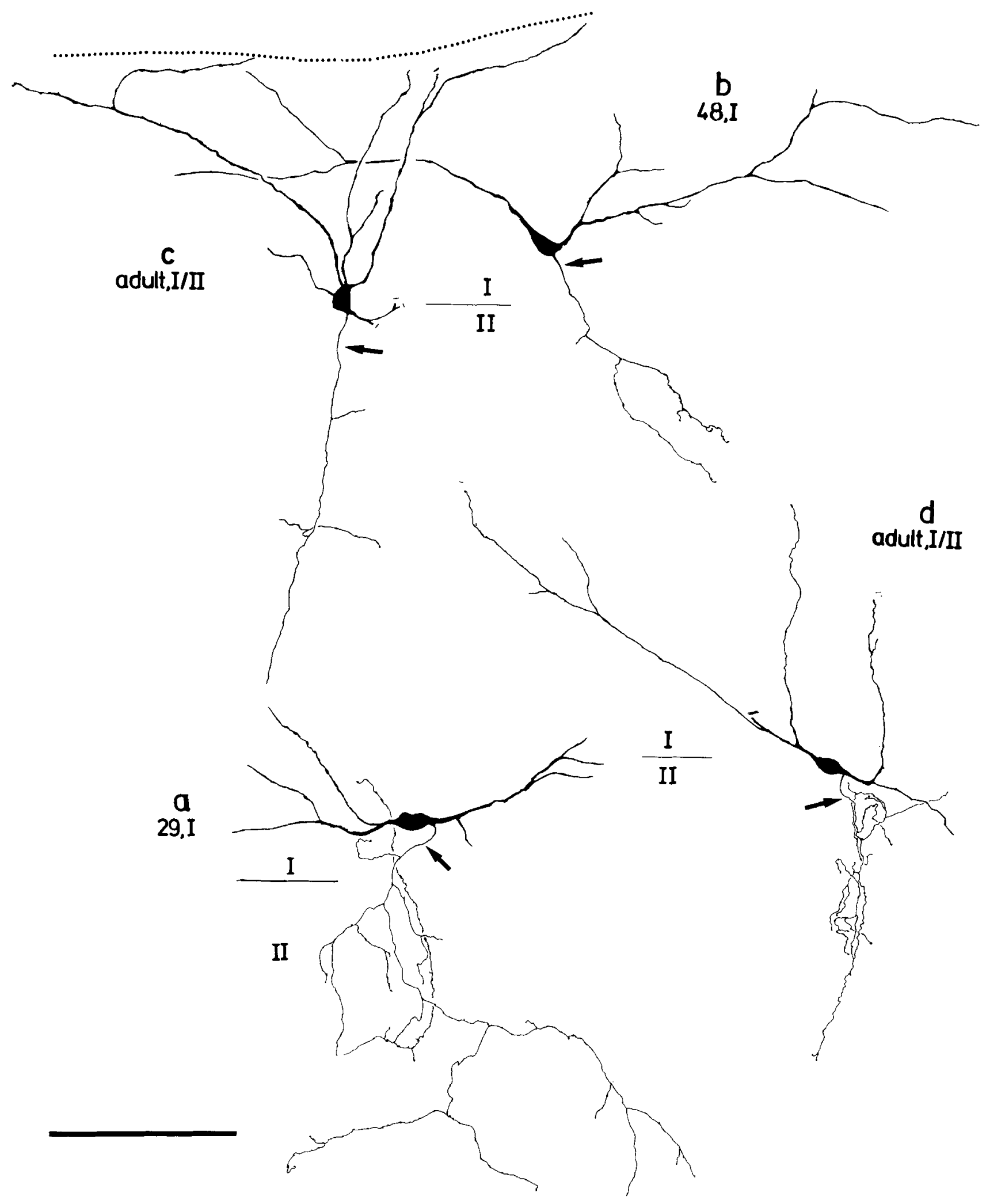

Fig. 11. Neurons of layer I. Note their unconspicuous axonal pattern. The layer I/II border is indicated; the dotted line in $\mathbf{c}$ marks the pial surface. VIP-ir neurons, a,b; PHI-ir neurons, c,d. Scale: $100 \mu \mathrm{m}$. 


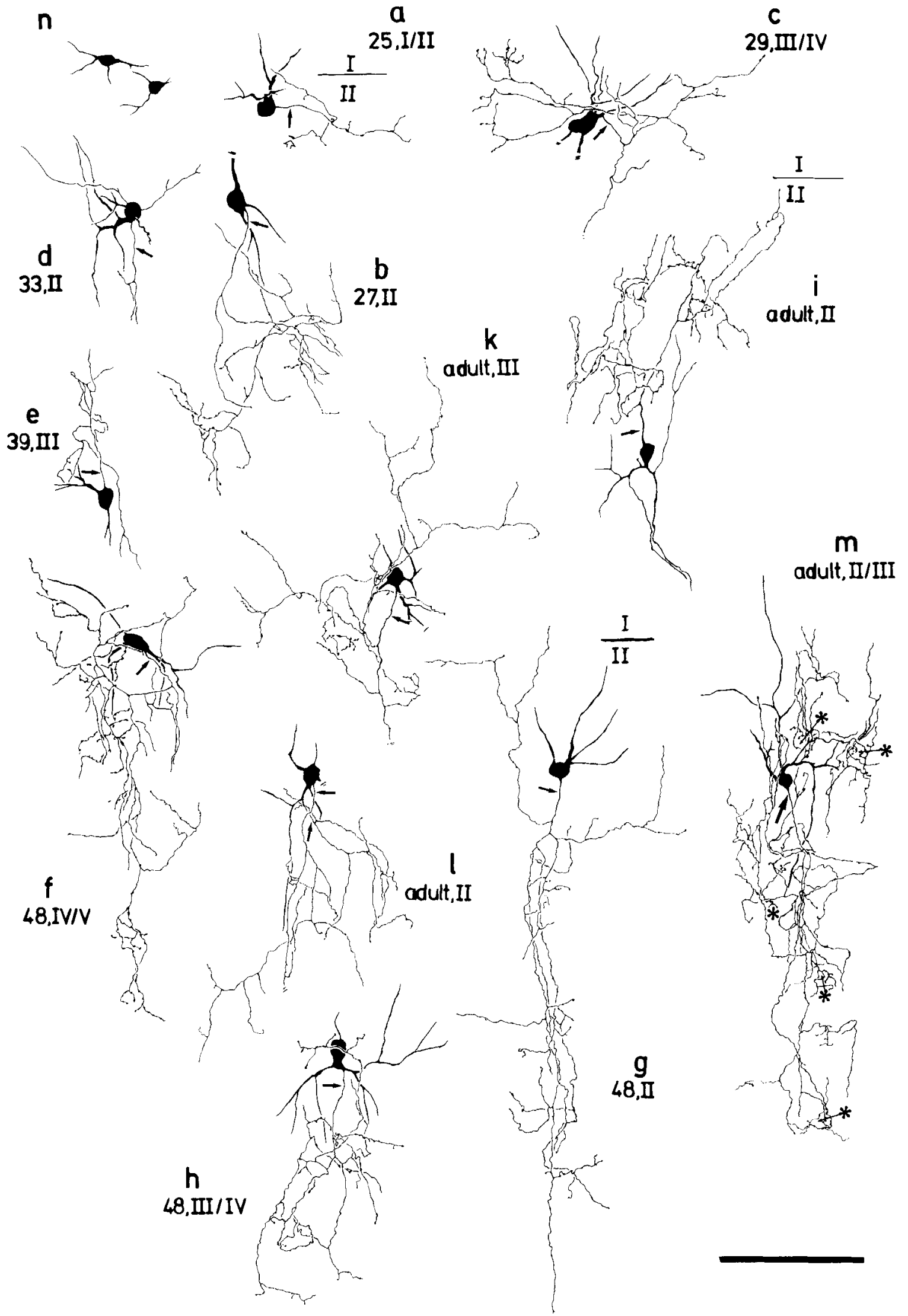

Fig. 12. Basket cells of the third population. n: Undifferentiated, putative basket neurons. In $\mathrm{m}$ some basket terminals are indicated by

asterisks. The layer I/II border is indicated in a,g,i. VIP-ir neurons, $\mathbf{a}, \mathbf{d}-\mathbf{f}, \mathbf{m} ;$ PHI-ir neurons, b,c,g,h,i,k,l,n. Scale: $100 \mu \mathrm{m}$. 

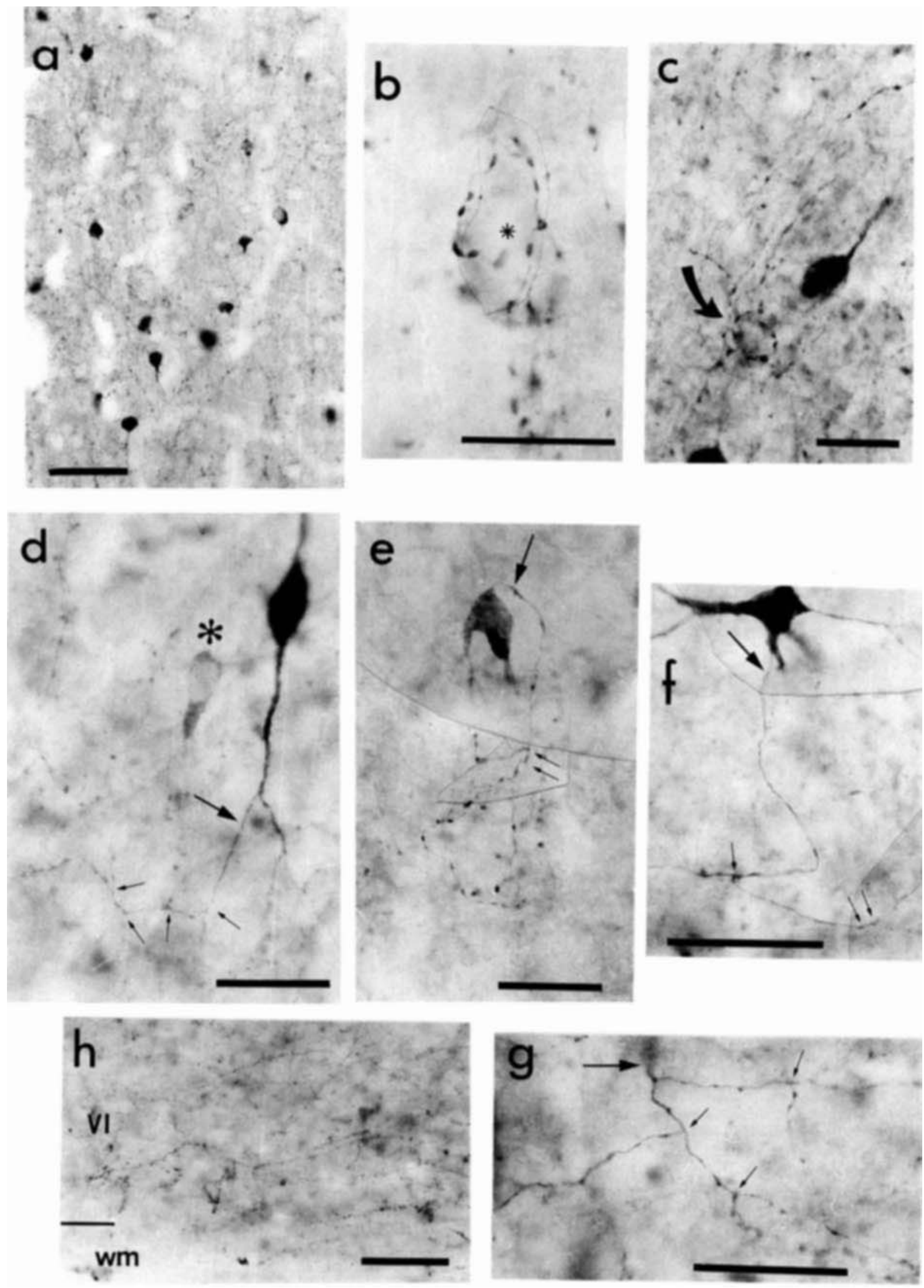

Fig. 13. a: Low-power photomicrograph shows layer III/IV at P 48 . Note the diffuse innervation by beaded fibers and the number of small somata. b: High-power photomicrograph of the terminal basket of one fiber which bends around a pyramidal shaped cell soma (asterisk) of layer III. c: Several fibers converge upon a cell body (curved arrow), thus forming a basketlike terminal pattern. d: Neuron with vertically descending main axon and horizontal collaterals. Fine arrows mark

branch points of the first collateral. The asterisk indicates an immature neuron possibly belonging to the basket cell population. e: Basket neuron; fine arrows mark the first branch points of the beaded axon. $f, g$ : Axonal ramifications of multipolar neurons of layer VI. h: Horizontal axons in layer VI. VIP-ir neurons, $c, d, f, h ;$ PHI-ir neurons, a,b,e,g. Scale: $100 \mu \mathrm{m}$ in $\mathrm{h} ; 50 \mu \mathrm{m}$ in a,f,g; $20 \mu \mathrm{m}$ in $\mathrm{b}, \mathrm{c}, \mathrm{d}, \mathrm{e}$. 


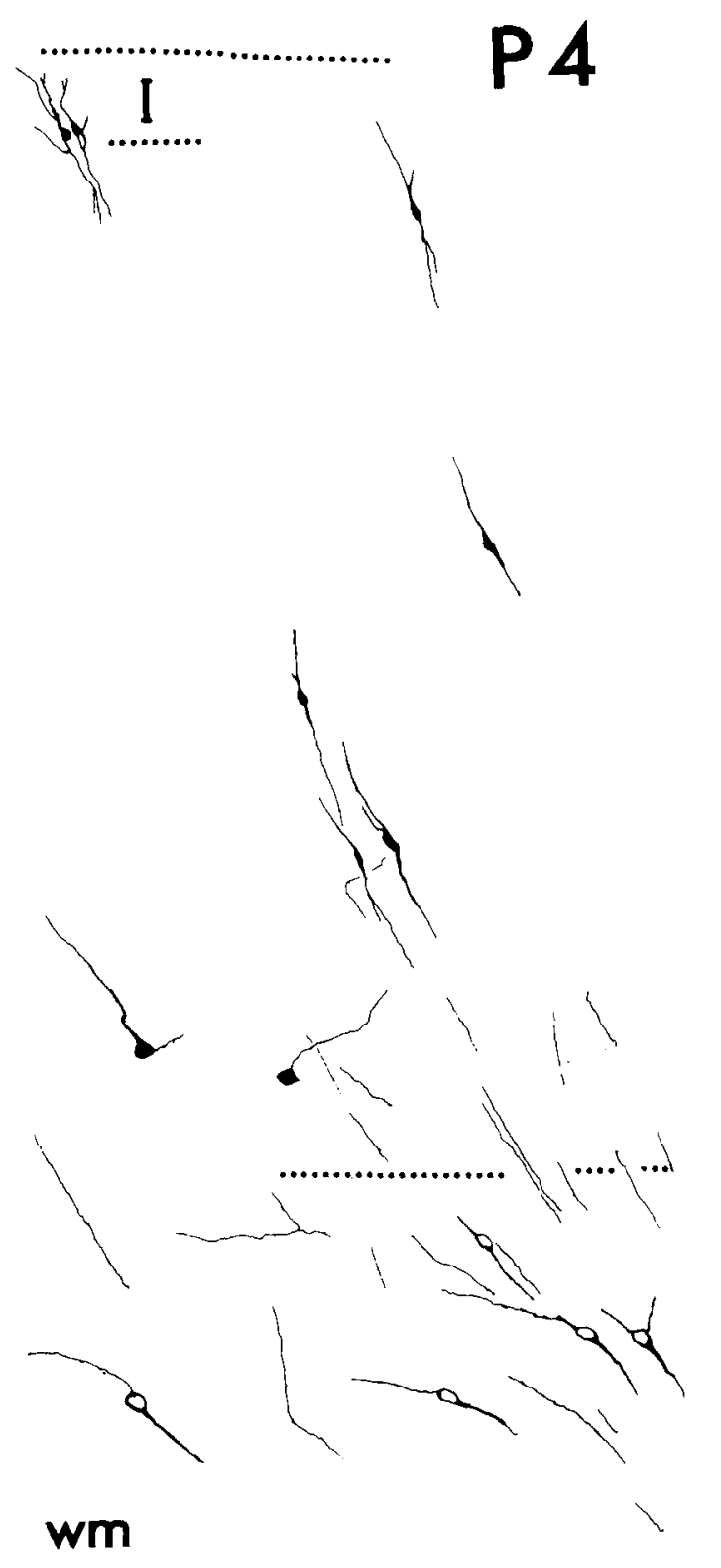

Fig. 14. The development of the VIP/PHI innervation pattern in area 17. The panels demonstrate characteristic features of IR at postnatal days $(P) 4,10,16,21,27,33,48$, and in the adult (1.5-year-old ani-

to a fully differentiated neuron belonging to the second population. Immature basket cells can be distinguished from immature bipolar cells because they do not display the conspicuous, eccentric "bubble" of the latter. By the sixth week the basket cells have formed a dense terminal plexus in layers III/IV (Fig. 13a), which becomes less dense toward layers V and II. The number of basket cells continues to increase in layer II until the seventh week. Concurrently a basket terminal plexus develops in layer II. After the second month the number of labeled somata in layer IV decreases.

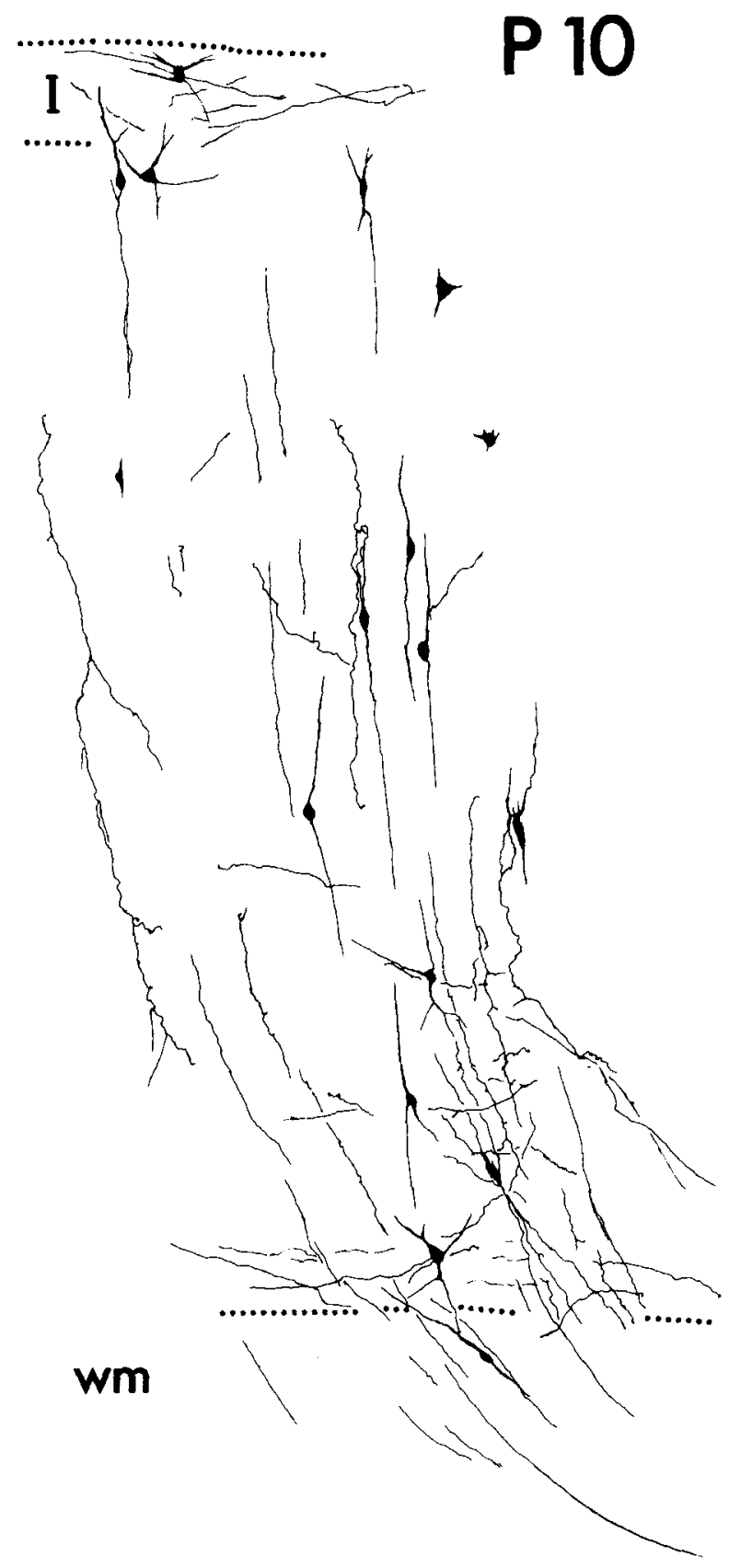

mal). PHI immunoreactivity; layer I and the border to the white matter (wm) is indicated. Scale: $200 \mu \mathrm{m}$.

Consequently, the terminal density in layer IV declines. In the adult cortex, basket cell somata lie mainly in layers II and III; some are still found in layer IV and occasionally also in deeper layers. A dense plexus is found in layers II and III (Fig. 16). The plexus now is less dense in layer IV (where it is mostly formed by the neurons with vertically descending main axon and horizontal collaterals) and only loose in layer VI (where it is mostly formed by the few multipolar neurons of layer VI and the neurons of layers $I I / I I I$ which project to layer VI). 

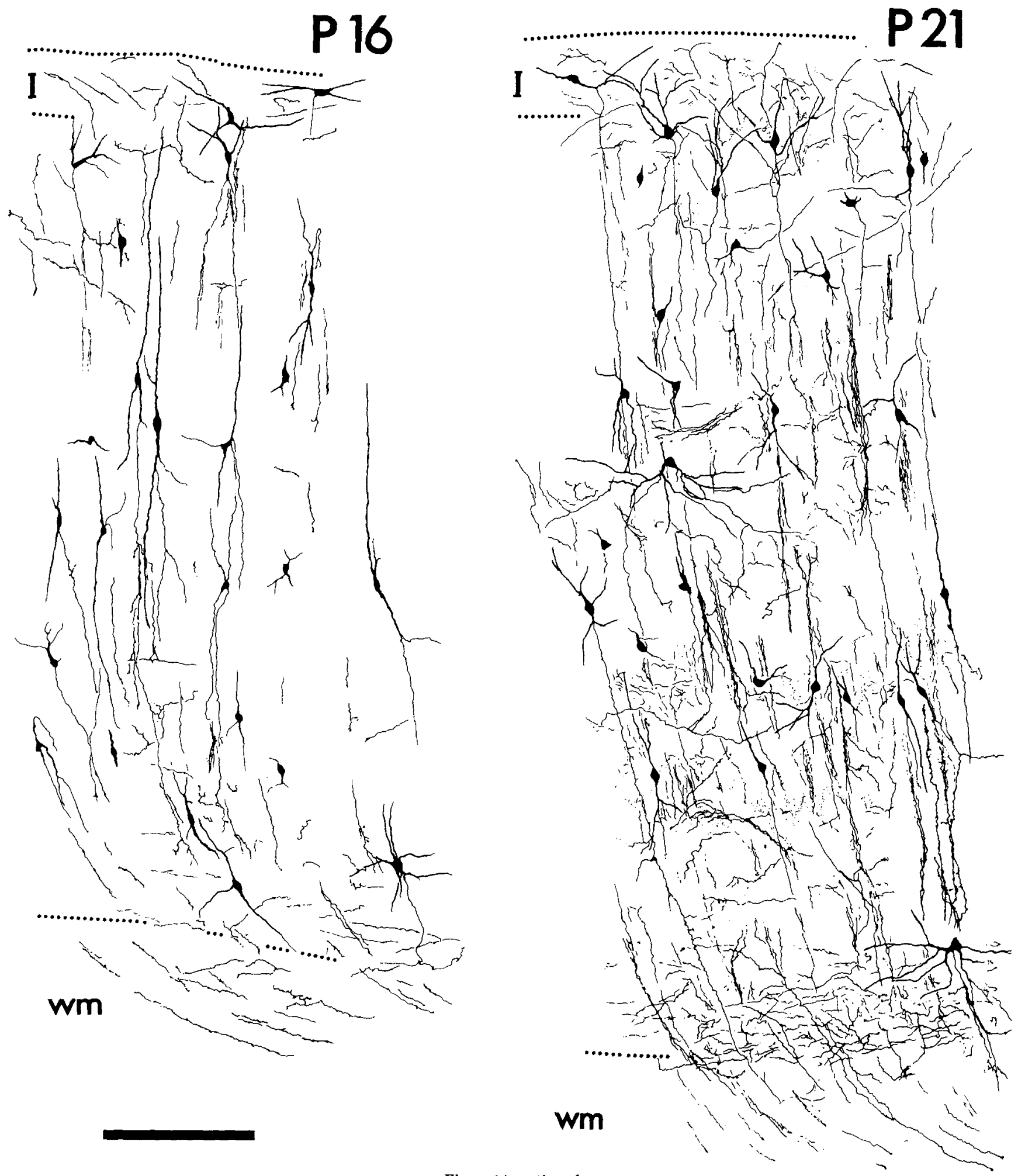

Figure 14 continued

\section{The developmental changes of the innervation pattern}

After having described the morphology of the VPI/PHI-ir neurons, we now will show the postnatal changes that occur in the VIP/PHI-ir innervation pattern in areas 17 and 18 Low-power camera lucida drawings of frontal sections from the medial flank of the postlateral gyrus are shown at $\mathrm{P} 4$,
$10,16,21,27,33,48$, and in the adult in Figure 14. It should be noted that in these low-power drawings fine fibers and terminals are not completely shown (compare the density of puncta in Fig. 14, P 48, to the photomicrograph in Fig. 13a). Pseudohorsetail cells are among the first VIP/PHI-ir neurons to appear in the visual cortex. They appear with an undifferentiated morphology at P 4 in layer I (Fig. 14, P 4). 


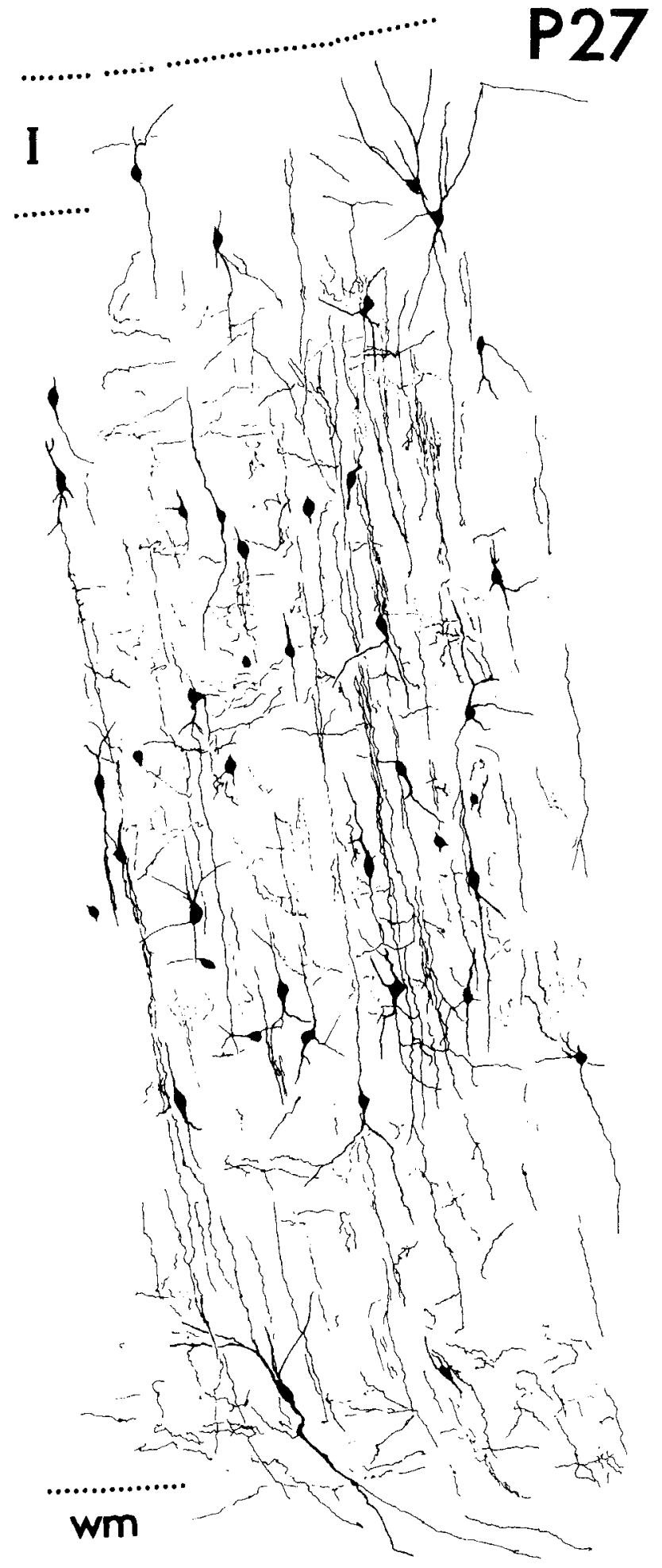

In deeper layers VI and V lightly stained, differentiating transient bipolar cells are found. In the superficial white matter some unclassifiable cell bodies can be identified. From P 7 onwards, better-differentiated pseudohorsetail cells appear (also in layer II), and transient bipolar cells are present in deeper layers. Their numbers increase during the following days (Fig. 14, P 10,16) and a maximum is observed

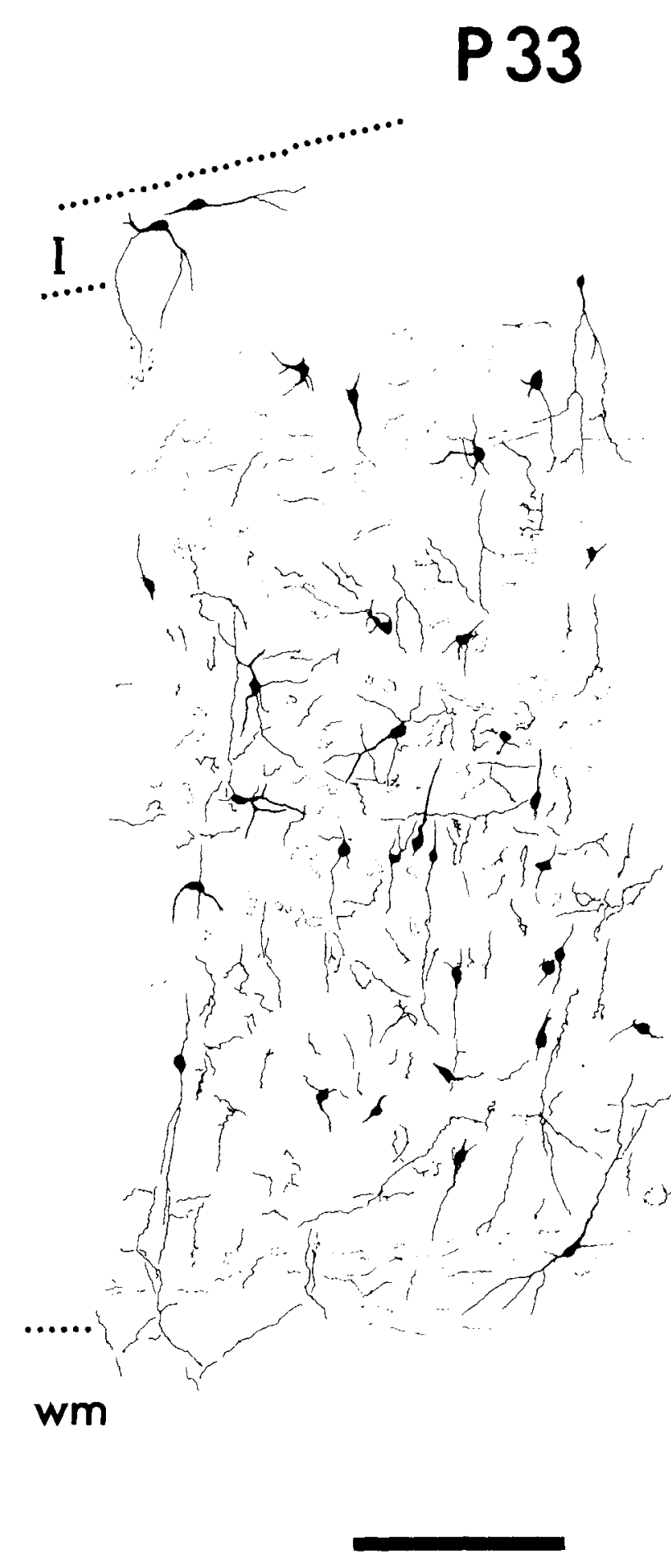

around P 21. During this period, the cortex is traversed by many long dendrites of transient bipolar cells, the axons of which project into the superficial white matter. The morphology of these cells gives the impression of a vertical architecture of VIP/PHI-ir structures. This impression is reinforced by many descending axonal bundles of pseudohorsetail cells (Fig. 14, P 16, 21). In addition, the fiber den- 

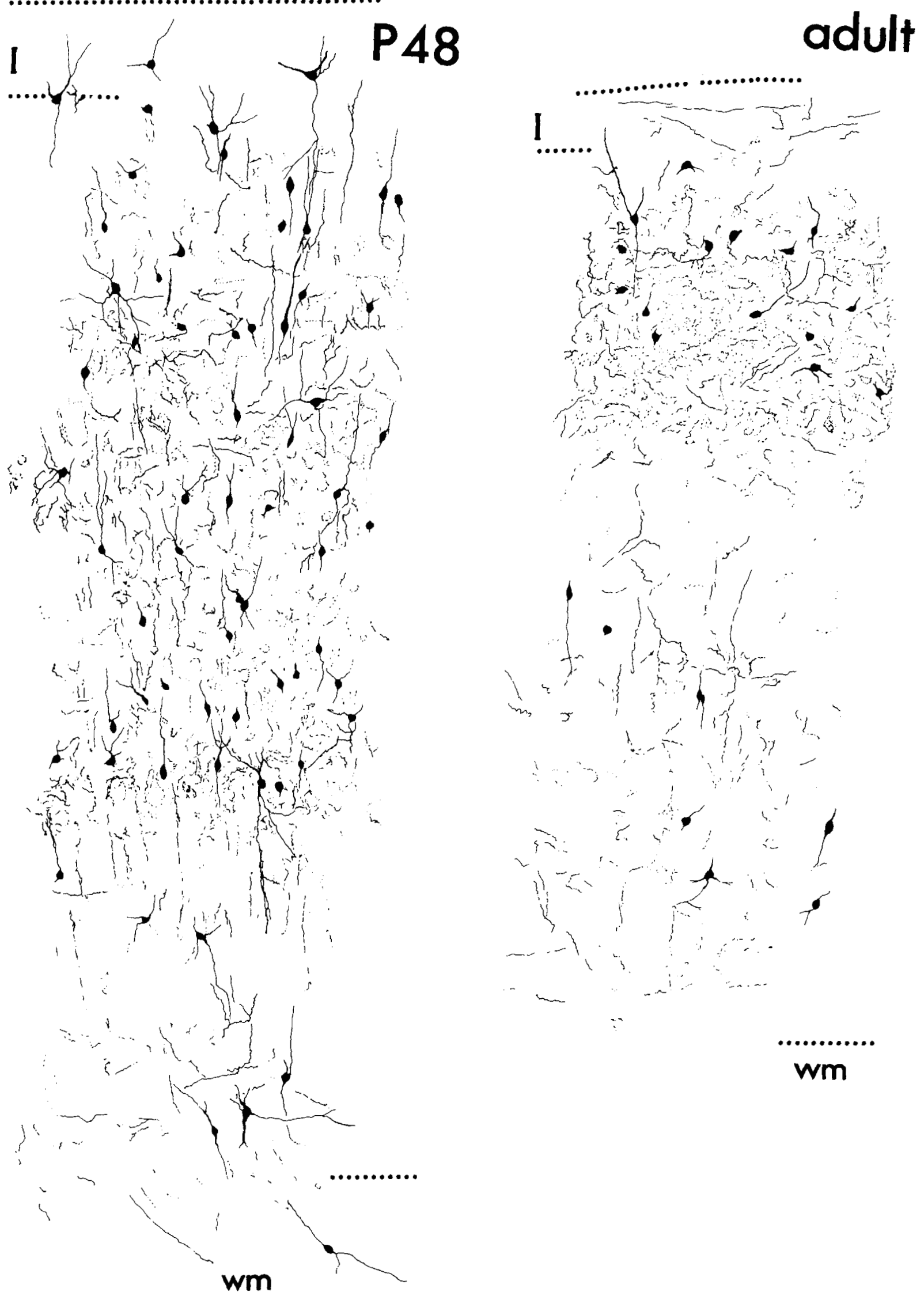

Figure 14 continued 


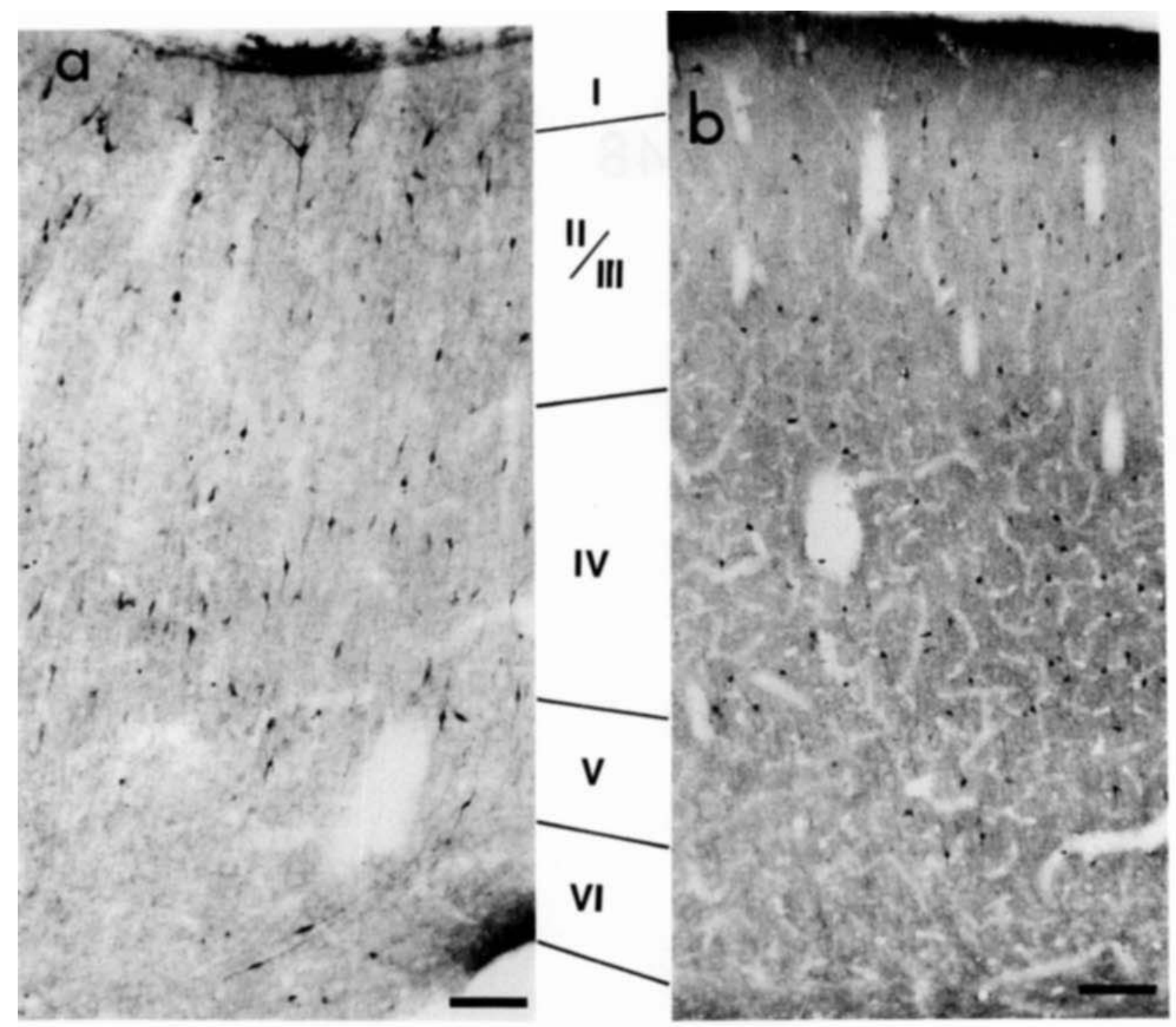

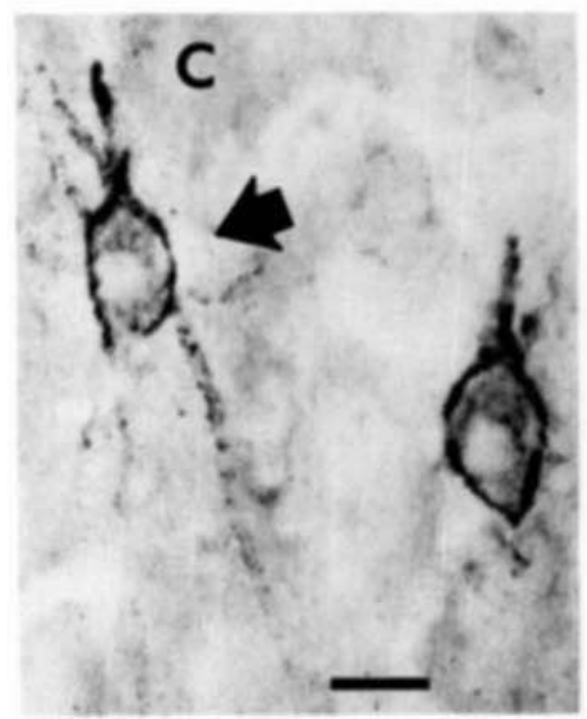

Fig. 15. a: Area 17 at postnatal day 25. The vertical orientation of ir structures dominates, many neurons are present in layer I. b: Area 17 at postnatal day 48. Diffuse innervation, layer I is largely devoid of ir somata. c,d: The outline of immunonegative pyramidal and nonpyramidal (c, thick arrow) neurons as produced by the anti-VIP antiserum in

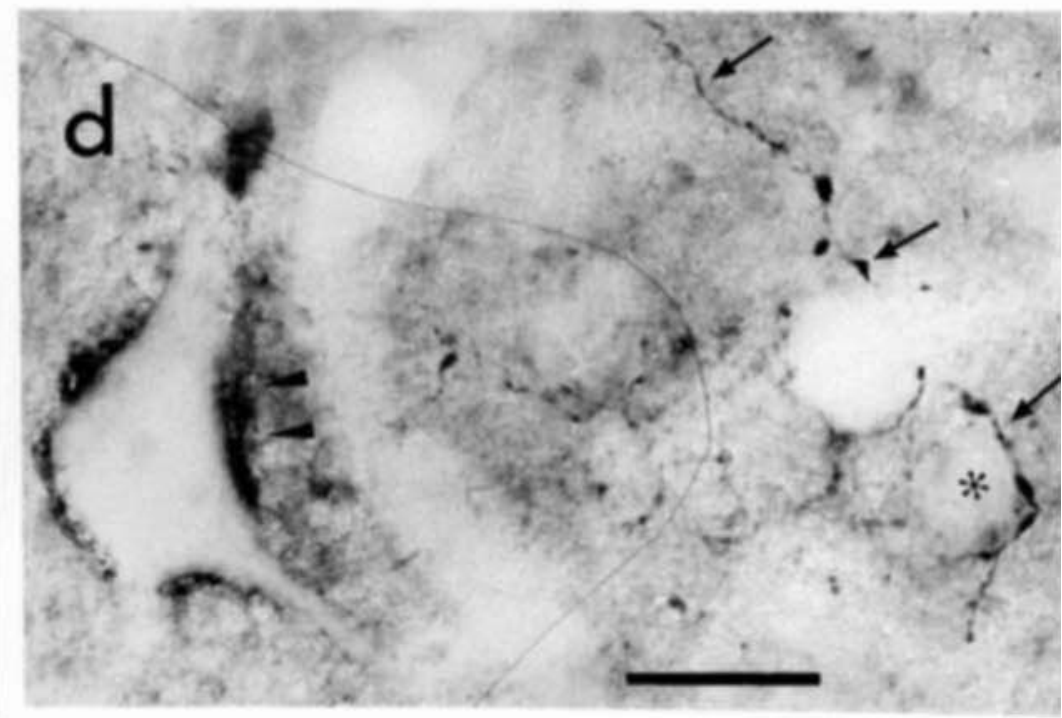

adult material. d: A beaded fiber (small arrows) just forms a basket terminal on the small cell body (asterisk) in the right half of the photomicrograph; the arrowheads point to a double-outlined membrane. VIP immunoreactivity in a-d. Scale: $100 \mu \mathrm{m}$ in $\mathrm{a}, \mathrm{b} ; 20 \mu \mathrm{m}$ in $\mathrm{c}, \mathrm{d}$. 


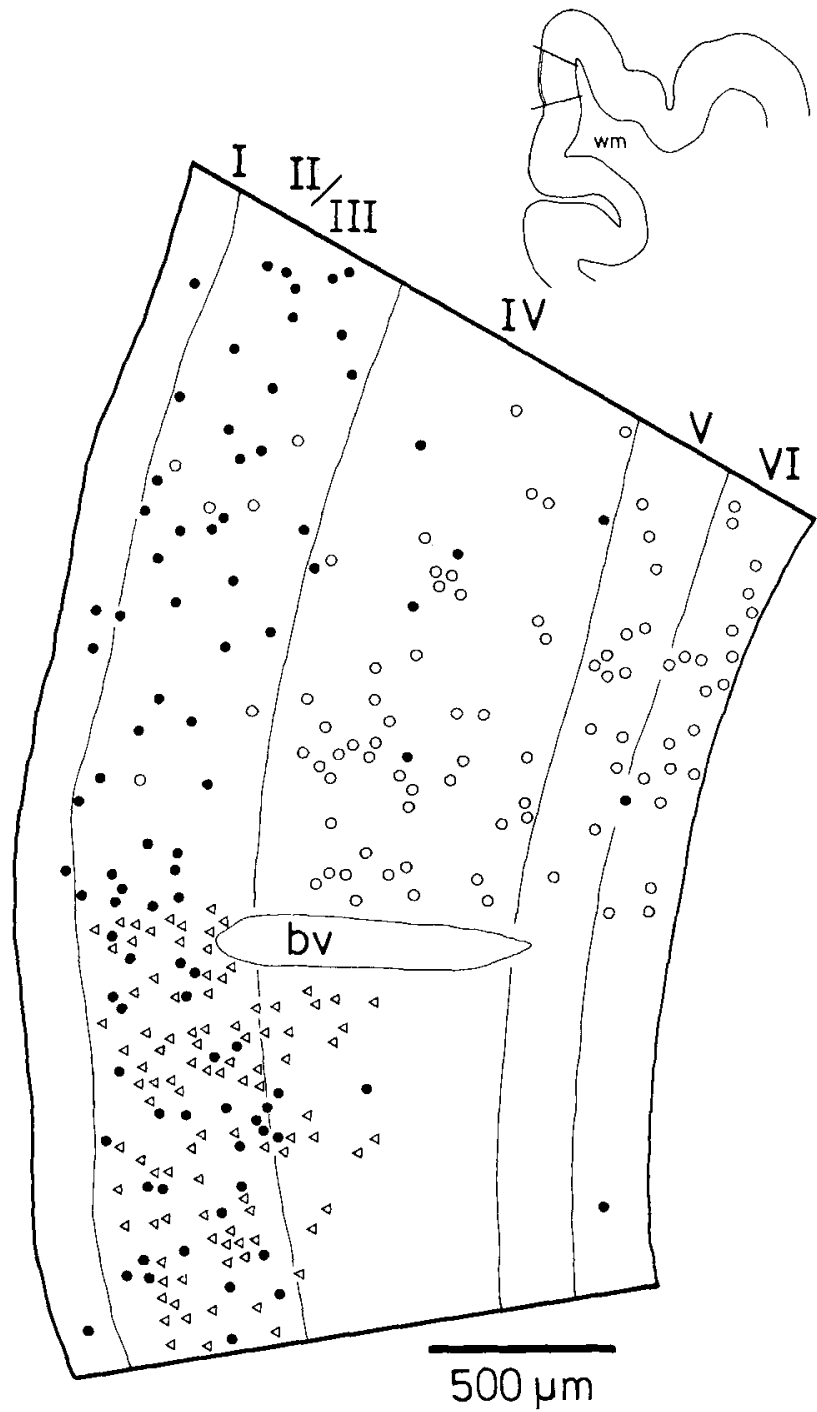

Fig. 16. The distribution of VIP-ir somata (black dots) in the adult cat area 17 (boxed area in the small schematic drawing). In the lower half of the drawing, we have plotted somata together with the basket terminals (open triangles); note that the distribution of somata and terminals overlaps. In contrast, in the upper half of the drawing the spatial relation between somata (black dots) and outlined neurons (open circles) is indicated; note that the distribution is largely non-overlapping. A large blood vessel (bv) was taken as a demarcation.

sity in layers I and VI (issued by pseudohorsetail cells) has increased.

By the end of the fourth week (Fig. 14, P 27) the number of pseudohorsetail and transient bipolar cells has decreased. As a consequence, the density of apical dendritic tufts and proximal axon collaterals of pseudohorsetail cells in layer I decreases, fiber bundles disappear from the cortical layers, and the density of the terminal plexus in layer VI is reduced to the adult level. Further, the projection of the transient bipolar cells into the white matter disappears. Both cell types disappear from the cortex during the fifth week. The first persisting bipolar cells with a differentiated local axon plexus appear by the end of the second week and their numbers increase slightly during the following weeks.
The first neurons belonging to the second population appear during the third postnatal week and increase in number during the following two weeks. Their axons form a loose organization of horizontal or oblique fibers and a diffuse terminal plexus mainly in layers II to IV thus initiating the change from the vertical to a more diffuse architecture. At the beginning of the second month the basket cells of the third population appear (Fig. 14, P 33). Before P 48 these neurons fill layers III/IV with a dense plexus of fine fibers and terminals. With the appearance of further basket cells in layer II also the terminal density increases. After P 48, cell and terminal density in layer IV declines, but persists in layers II/III (Fig. 14, adult). The change from the initially vertically oriented cell and fiber array (Fig. 15a at $P$ 27) to a diffuse one without preferential orientation (Fig. 15b at $P$ 48 ) is now complete. Note, in Figure 15, that layer I and the border to layer II are nearly devoid of ir neurons. The distribution of somata (black dots) and basket terminals (triangles) in the adult cats area 17 is indicated schematically in Figure 16. The same pattern occurs in area 18.

It is noteworthy that in the course of this study we have observed a staining pattern quite different from that seen normally in material stained with antineuropeptide antisera. It is documented in Figure 15c,d. The VIP-antiserum, but not the PHI-antiserum, recognizes an (apparently membrane-associated) epitope in neurons which are not immunoreactive for VIP. The staining produces an outline of the cell body. As can be seen in Figure 15d, this outline is not a blurred basket terminal pattern. Rather, it appears as a quite intense labeling of the cell's outer membrane. Sometimes, a fenestrated pattern is visible (Fig. 15d). Two neuronal classes are labeled in this way. In pyramidal-shaped cells the labeling is confined to the soma and spreads only for a short distance into the dendrites. Other neurons can be recognized as multipolar or bitufted and non-pyramidal in shape (Fig. 15c, arrow), because in these cells, the epitope is also present in more distal parts of the dendritic tree. Axons were never labeled. The distribution of outlined neurons is shown in Figure 16 (the open circles). It can be seen that they are located mainly in deeper layers and thus are spatially separated from the VIP-ir neurons and their basket terminals. Interestingly, we have identified the outline pattern only in adult animals: it is not apparent before or at $P$ 48 (Fig. 15b).

\section{DISCUSSION General observations}

Our morphological and chronological analysis of the development of VIP- and PHI-ir structures has revealed that both peptides occur in cortical neurons which, morphologically, belong to the same cell types. The VIP- and the PHI-ir neurons of these respective types occur in the same cortical layers and appear with the same postnatal chronology. Because the double-staining procedures do not result in more cells per section than single stainings, we assume that the two peptides are colocalized in visual cortical neurons. Biochemical data indicate that both peptides are transcribed from a single precursor gene which probably has evolved by duplication of an archaic gene ancestral to both peptides (Bishop et al., '84; Fahrenkrug et al., '85; Linder et al., '87). Our finding thus confirms immunohistochemical data obtained in other structures (Okamura et al., '86). Most of the cell types we characterized in the present report appeared equally well stained with each of the two antisera; 
only in the transient bipolar cells did we have the impression that a somewhat more complete morphology was revealed by the VIP-antiserum.

However, a real difference can be seen in the adult cortex, where the neuronal outline pattern was observed only in VIP-stained material and not even faintly present in PHIreacted sections. Our anti-VIP-antiserum also outlines neurons in deeper layers of the rat and marmoset (Callithrix jacchus) neocortex (unpublished observations). In the rat, the pattern does not occur in animals younger than three weeks; young marmosets have not been investigated. The outline is present only when specific VIP-ir structures are also labeled, e.g., the bipolar cells in the rat; its intensity decreases with increasing dilution of the antiserum; and it disappears after preabsorbing the antiserum with the peptide. We do not know what kind of substance crossreacts with the VIP antiserum used; possibly, an epitope is shared between VIP and the membrane-bound molecule. Quite similar staining patterns in the cat visual cortex have been recently reported by Arimatsu et al. ('87) and Naegele et al. ('88), and they have been obtained with monoclonal antibodies against molecules much higher in molecular weight than VIP.

The morphological differentiation of the VIP/PHI-ir neurons of the cat cortex occurs entirely postnatally. This has also been observed in the rat (Emson et al., '79; McDonald et al., '82; Hares and Foster, '88). In rat telencephalon, the concentrations of VIP and PHI (Christofides et al., '83a) begin to increase during the first postnatal week. Emson et al. ('79) and McDonald et al ('82) reported that in the rat cortex, the first immunoreactive neurons appeared in layers VI and $\mathrm{V}$, followed by the appearance of immunoreactive perikarya in more superficial layers. In the cat, we observed that the first neurons appear more or less concurrently in layers I and V/VI at around P 4. The superficial white matter also contains labeled cell bodies. However, these cells could not be classified according to morphological criteria, nor did we observe distinct patterns of differentiation or degeneration. Their form and number do not resemble those of other, known components of the white matter, e.g., neuropeptide $\mathrm{Y}$, somatostatin, or glutamic acid decarboxylase-immunoreactive (GAD-ir) neurons (Wolff et al., '84; Chun et al., '87; Wahle and Meyer, '87a; Wahle et al., '87). Furthermore, they do not look like migrating neurons (Rakic, '72); their somata are quite large and the processes are not arranged radially. Their fate could not be determined in our investigation.

\section{The pseudohorsetail cells}

The first unequivocal neuronal type that was identified in our study has been termed pseudohorsetail because its descending axonal bundles resemble those of the true horsetail cells (Szentagothai, '73) of the adult cortex. However, true horsetail cells are not peptidergic, their somata are localized in layer II and III, they often form more than one axonal bundle per cell, and they do not terminate with horizontal fibers in layer VI (Meyer, '83). Furthermore, they have a different postnatal chronology of maturation: true horsetail cells can not be identified before $P 15$ and reach their adult shape around P 40 (Meyer and Ferres-Torres, '84).

The prominent features of the VIP/PHI-ir pseudohorsetail cells are their position mainly in layer I, the orientation of most dendrites and proximal axon collaterals towards this layer, and their axonal projection restricted to layer VI.
From their position and transient nature, we presume that the cell type originates in the marginal zone. All the neurons of layer I originate from the marginal zone which is generated with the subplate at embryonic days 26/27 (Luskin and Shatz, '85a). Neurons which are generated later are destined only for cortical plate layers II to VI (Luskin and Shatz, '85b). This implies that pseudohorsetail cells differentiating in layer I must have already arrived in this layer at an early embryonic stage. When the arriving neurons of the cortical plate then divide the two components of the "primordial plexiform layer" (Marin-Padilla, '71), the demarcation between the subplate and the marginal zone with the cortical plate may not be very strict, so that some subplate and marginal zone neurons located at the prospective laminar borders may intermingle with neurons of the cortical plate. Furthermore, during the first two postnatal weeks neurons destined for layers II/III are still migrating (Shatz and Luskin, '86), while pseudohorsetail cells have already established mature axonal projections to the postmigratory layer VI. These fully differentiated pseudohorsetail cells do not comigrate with the immature cells of layers II/III, which must overtake them in the course of segregation of superficial layers. Thus, some pseudohorsetail cells may become passively situated among cortical plate cells. This mechanism could explain the morphological characteristics of the pseudohorsetail cells, for example, the variant with the hook-shaped basal dendrite: recurrent axon collaterals and even dendritic tufts are oriented toward layer I because the neurons lie among undifferentiated, migrating cells in an undefined lamina which is largely avoided by specific input (Shatz and Luskin, '86). The descending axonal bundles cross the layers which contain migratory neurons, on the shortest (vertical) way to reach layer VI. The pyramidal cells in layer VI have already started differentiation and reach a more-or-less adult shape during the second postnatal week (own Golgi observations). They represent a possible target for the VIP/PHI-ir layer VI plexus, as would be other mature neuronal types in layer VI, e.g., multipolar VIP/PHI-(the present paper) and CCK-ir neurons (Meyer and Wahle, '88), or transient neuropeptide Y-immunoreactive (NPY-ir) neurons (Wahle and Meyer, '87a). Transient neurons of the marginal zone may thus functionally interact with persisting neurons during a certain period of development.

\section{The bipolar cells}

Two forms of VIP/PHI-ir bipolar cells have been distinguished. The position of the majority of transient bipolar cells in cortical layers IV, V, and VI clearly argues for a cortical plate origin and reveals the existence of transient cell types outside the subplate and marginal zone. The transient bipolar cells are the only cell type observed so far which are probably derived from the cortical plate and which project and terminate in the upper white matter. Here, the upper subplate neurons constitute a likely target. Indeed, the transient bipolar cells type seems to depend on the presence of the subplate. The VIP/PHI-ir projection begins to form when the NPY-ir neurons of the upper subplate start differentiation, and it reaches a maximal level during the period when many NPY - and GAD-ir neurons (Wahle et al., '87) and also somatostatin-ir neurons (Wahle, in preparation) exist. Most transient bipolar cells disappear around the end of the first month. Our GAD data indicate that at this time, cell and terminal density (and therefore the total breadth of the upper subplate) decrease (Wahle et al., '87). 
A significant loss of cells from deeper cortical layers during the early postnatal period has also been reported for the monkey (O'Kusky and Colonnier, '82) and mouse cortex (Heumann and Leuba, '83). Cavanagh and Parnavelas ('88) have reported disappearance of somatostatin-ir neurons by cell death from the rat cortex.

We suggest cell death to be the reason for the disappearance of transient bipolar cells because degenerating cells are observed. A morphological transformation into persisting bipolar cells is unlikely for the following reasons. First, if neurons depend on a supply of target-derived trophic factors (Thoenen et al., '87) they would probably not survive the degeneration of axon plexus without forming a new one (Cowan, '70; Lieberman, '71). Thus, one would expect to see a completely different axonal plexus at times when the original axon plexus is still present. Transformation via the concurrent presence of both, a transient and a persisting axon plexus has been clearly demonstrated in identified neurons, the H-cells of an insect embryo (Goodman et al., '81). In cat cortical neurons such a process was not observed. Second, transient bipolar cells would have to migrate towards superficial layers to reach the position of the persisting bipolars; however, there is no evidence for the migration of fully differentiated neurons. Third, there is a temporal overlap with persisting bipolar cells already appearing before transient bipolar cells disappear. Furthermore, it is unlikely that they transform into other VIP/PHI-ir cell types because, especially in the adult, the deeper cortical layers are largely void of VIP/PHI-ir neurons.

\section{Transient neurons}

The existence of a cortical cell type with all members becoming eliminated after a certain period of development has already been discussed (Wahle and Meyer, '87a; Meyer and Wahle, '88; Wahle, '87). We suggest that these transient types are eliminated after they have fulfilled some specific (as yet unknown) function. VIP/PHI-ir pseudohorsetail cells and transient bipolar cells undergo degeneration with symptoms which are similar to those described for NPY-ir axonal loop cells (Wahle and Meyer, '87a) and to some degree also for aging neurons in vivo (Peters et al., '74) and in culture (Romijn et al., '84; Martin et al '88). Fine structural analyses have confirmed these symptoms as signs of cell death (Matthews, '73; Chu-Wang and Oppenheim, '77), especially also during postnatal development of the cat neocortex (Valverde and Facal-Valverde, '87, '88). While the NPY-ir axonal loop cells of the white matter show unequivocal signs of cell death (disintegration) we have only occasionally found such signs in the gray matter, in the present study, and in our CCK-ir material. The reason may be that the peptides are immediately degraded in the stage of cell lysis by peptidases which could be present in high quantity in the gray matter to inactivate peptide transmitters (Schwartz, '83; Kenny, '86; Strittmatter et al., '86). Especially some of the pseudohorsetail cells have an unfortunate position between migratory cells which are reported to secrete proteases (Seeds et al., '87). Alternatively, VIP and PHI (at least the epitopes recognized by the antisera) may not be as stable as NPY and become nonreactive during cell lysis.

Apart from cell death, morphological transformation has been discussed as a possible reason for the disappearance of neuronal types (Bradford et al., '77; Marin-Padilla, '72). We have already suggested above that such a process is unlikely for the transient bipolar cells and we are inclined towards the hypothesis that pseudohorsetail cells also die. It is clear that they do not transform into true horsetail cells, because the latter have a different soma position and chronology of maturation which can be followed in Golgi material (Meyer and Ferres-Torres, '84). However, we cannot exclude the possibility of axonal reorganization in some neurons of the latter cell type. The reason is that around the end of the pseudohorsetail cell period VIP/PHI-ir neurons of layer I appear with dendritic trees which are quite similar to those of pseudohorsetail cells. Only the axon is different: it simply terminates in superficial layers without issuing a complex axonal pattern. It is possible that some pseudohorsetail cells have rejected the descending bundles and retracted the ascending collaterals, and thus have developed other connections within superficial layers. A comparable process has been described by Innocenti et al. ('86) for layer III pyramidal cells which project transiently to the contralateral hemisphere, and by O'Leary and Stanfield ('85) for other pyramidal cells of the occipital cortex which project transiently into the pyramidal tract. However, the density of pseudohorsetail cells during development (P 0-P 30) is much higher than the density of persisting layer I cells in the young adult cortex (P 30-adult), so that it can be safely assumed that the majority disappear by cell death. Indeed, some have already degenerated in the course of the neuronal turnover (see below) a few days after the cell type has first appeared. These cells thus disappear three weeks before the neurons of layer I become recognizable. A considerable loss of cells from layer I from birth to 3 months was also reported for monkey (49\%; O'Kusky and Colonnier, ' 82 ) and rat visual cortex ( $46 \%$; Bradford et al., '77). The loss of pseudohorsetail cells seems not to be caused by a loss of immunoreactivity in the somata and loss of immunoreactivity in the axons due to myelination. In this case, at least the preterminal and terminal portions of the axons in layer I and VI should remain recognizable (terminals are not myelinated). However, terminal density is clearly reduced in layer VI in the adult. Furthermore, pseudohorsetail cells have not been identified as components of late postnatal or adult cat visual cortex by other anatomical methods, for instance the Golgi method (Meyer, '83; Meyer and Ferres-Torres, '84).

Pseudohorsetail and transient bipolar cells do not differentiate at the same moment but heterochronously: From P 4 to $P 7$ we observe mainly differentiating cells of both types. From $\mathrm{P} 7$ to $\mathrm{P} 10$ also mature cells are present. From P 10 onwards we found morphologically immature, fully differentiated and already degenerating neurons of the types side by side. We assume a certain turnover for the individual members of each types because cell density and innervation density neither increases-as would be expected by the presence of newly differentiating cells-nor does it decrease because of dying cells. This suggests that a fully differentiated neuron remains present only for a few days and is substituted by a cell of the same type which has started maturation somewhat later than the first one. Indeed, we observed degenerating cells only a few days after the first fully differentiated individuals of a given type were seen. The turnover continues into the fourth week, were mature and degenerating neurons are found, but no longer immature ones. Around P 27 mostly degenerating neurons are found, and pseudohorsetail and transient bipolar cells disappear at around $\mathrm{P} 30$. A consequence of such a process would be that the terminal pattern in layer VI and in the superficial white matter undergoes a turnover with degenerating connections being superseded by new ones. 


\section{CELL TYPE}

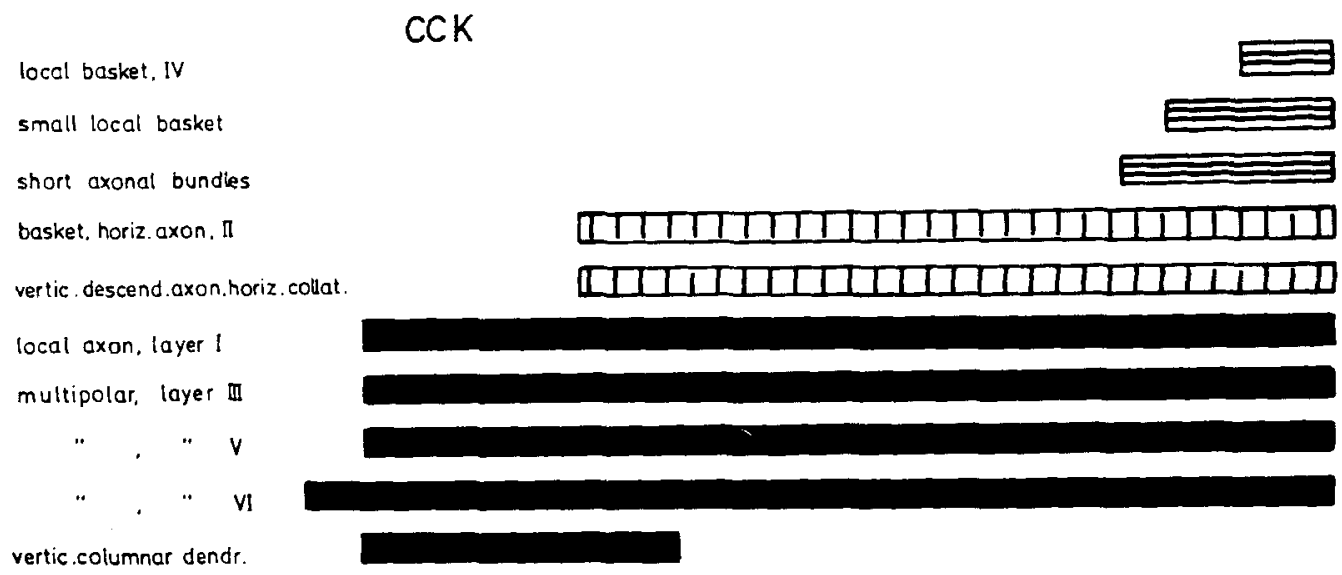

VIP/PHI

local basket
layer I
vertic. descend. axon, horiz. collat.
bipolar, local axon
multipolar, layer III
". VI
vertic.columnor dendr.
transient bipolar
pseudo-horsetail

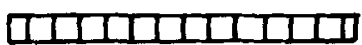
पामामामामा

NPY

local basket
early white matter
early grey matter
axonal loop
bituited rectangular
pseudopyramidal
small multipolar
unitufted

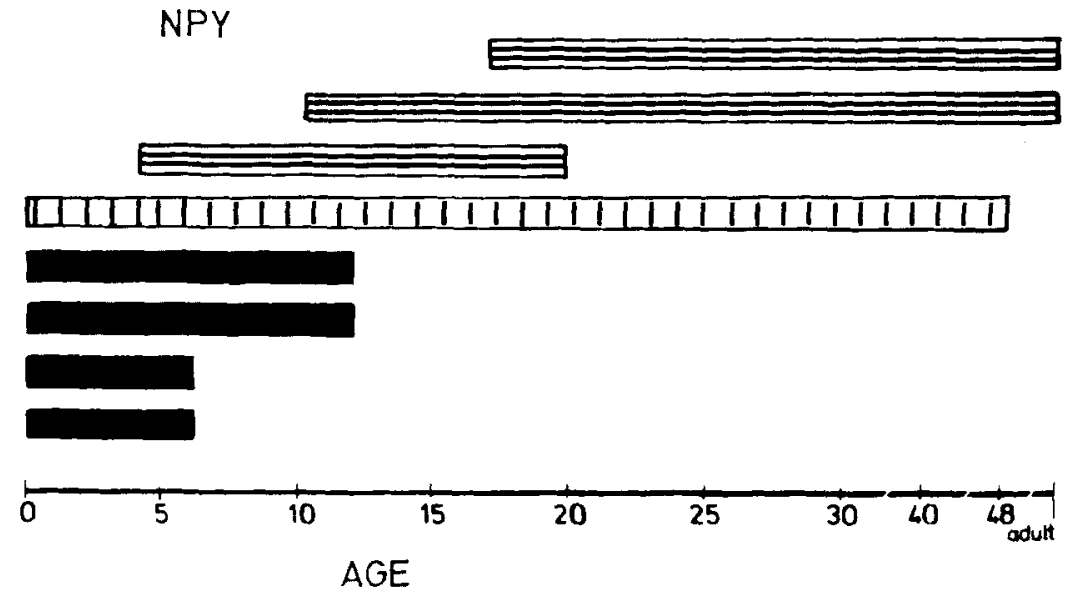

$\infty 1$

IIIT 2

\section{$\equiv 3$ population}

Fig. 17. Summary diagram showing the chronology of appearance and/or disappearance of NPY-, VIP/PHI-, and CCK-immunoreactive cell types of the neuronal populations (indicated) from postnatal day 0 to adulthood. Most cell types appear peri- or postnatally; only the four types of the first population of NPY-ir cells may have their peak prenatally. 


\section{Persisting types of the first population}

The persisting neuronal types of the first, but also those of the second and third population are probably derived from the cortical plate, because they appear in the gray matter. The VIP/PHI-ir persisting bipolar cells in the young and adult cat visual cortex are morphologically similar to Golgi-impregnated bipolar cells described by Meyer ('83) and Meyer and Ferres-Torres ('84). They begin to differentiate when the superficial layers have separated around the end of the second week (Shatz and Luskin, '86) and are present in moderate numbers during the following weeks. In the later postnatal period they are less common than the basket cells of the third population, and they do not form a very common type in our adult material. Only a few were identified unequivocally by axonal criteria. Bipolar cells are also rare in Golgi material of the adult cat cortex (Meyer, '83) and they are not present in the human motor (Meyer, '87) and auditory cortex (Meyer, unpublished observations).

Another early appearing VIP/PHI-ir cell type is the multipolar neurons of layer $V I$ with intralaminar axons. The cells have isolated positions and seem to possess axonal territories, because the axons of neurons located exceptionally close to each other occupy opposite, thus largely independent domains. The neuronal turnover suggested above may also account for these cells: although they belong to a persisting type, degenerating individuals are found while others differentiate. The bitufted to multipolar neurons of layers II/III appear at around the end of the second week. They maintain a VIP/PHI-ir connection from superficial to the deep layers persisting into adulthood. During development, these types contribute to a terminal plexus which is largely supplied by transient pseudohorsetail cells, and they maintain a reduced innervation of layer VI during adult life. In the adult, they are largely outnumbered by the small basket cells of the third population. In contrast, in our CCK-ir material multipolar neurons of layer VI and bitufted to multipolar neurons of layer II/III occur far more frequently and issue a fairly dense layer VI terminal plexus that persists through adult life.

\section{The adult innervation pattern}

During the third and fourth week neurons of the second population appear. The appearance of the diffuse axon plexuses of the neurons with vertically descending main axon and horizontal collaterals heralds the change from the transient, radially oriented architecture. The rather diffuse and unconspicuous axons of neurons of layer I contribute to the innervation of superficial layers. The change is complete when the transient cell types have disappeared and the neurons of the third population have filled layers II-IV with a dense basket terminal plexus. The local basket cells are the latest to appear, and this is in agreement with our findings in CCK-ir and NPY-ir material (Fig. 17). The late postnatal appearance of local basket neurons may indicate that local connectivity becomes more and more refined as development proceeds. Interestingly, the VIP/PHI-ir basket cells appear first in layers IV/III and later in more superficial layers III/II; concurrently the stratum of highest terminal density shifts from layer IV to layers III/II. After the second month the cell density declines in layers II-IV. This reduction, however, is stronger in layer IV than in layers II/III, and in the adult animals layer IV contains rather few somata.

This late postnatal reduction in cell number probably affects all cell types present in the cortex at that time.
Because these cells appear to display a similar degree of maturity, this cell loss may have a random character, perhaps an oversupply of neurons no longer necessary in the adult becomes eliminated (Hamburger and Oppenheim, '82). Regressive events are common during ontogenesis (Glücksmann, '50; Cowan, '73; Hamburger and Oppenheim, '82; Cowan et al., '84) and competition between neurons for the available target or population matching (Sengelaub et al., ' 86 ; Finlay et al., ' 87 ) may be the reason for the cell loss. For example, in the monkey visual cortex $16 \%$ of the neurons are lost from all cortical layers during postnatal development. In addition, the number of synapses decreases (O'Kusky and Colonnier, '82). However, in the present study signs of degeneration and cell death were seldom observed during the late postnatal phase. The reason for this may well be that degeneration proceeds quickly (Heimer and Kalil, 78) and cellular debris is rapidly removed. It is, however, possible that a number of somata become invisible because the amount of peptide sinks below the level of detection within the somata, a process reported for peptide immunoreactivity in retinal ganglion cells (Kuljis and Karten, '86). Terminal strata of ganglion cell axons, however, remain detectable. In our case, both VIP/PHI-ir somata and their local axon plexuses disappear in layer IV. It is thus possible that the small basket cells in layer IV do not die but only transiently express VIP/PHI-ir and cease the production in adult cortex. Such a process was identified in Martinotti cells of the early postnatal cat cortex which express substance $P$ only during development (Wahle et al., '88) and it also results in a "disappearance" of cells due to a decrease of staining intensity. From our material we can not decide whether the subset of VIP/PHI-ir small baskets in layer IV disappears by cell death or by loss of peptide immunoreactivity. However, the latter process should not be confused with the specific elimination of cell types discussed above. In the course of degeneration neurons of pseudohorsetail and transient bipolar cell type become intensely immunoreactive, and this rather argues for an overproduction and/or disturbance of release of peptide than a cessation of production.

\section{Similarities between VIP/PHI-ir and CCK-ir neurons}

Some further points deserve comments. An interesting finding is that neurons of certain cell types may send out two axons instead of only one. This was often found with multipolar neurons of layer VI, neurons with columnar dendritic fields, but also basket cells. In all cases both axons looked equivalent and both formed terminal varicosities. Double axon cells were also observed in our CCK-ir material in neurons of the same morphological types. Freund et al. ('86), who analyzed CCK-ir double axon cells, confirmed the axonal nature of both fibers. We had the impression that the primary role is the formation of a specific innervation pattern and that it is of minor importance whether this task is carried out by one or more fibers.

When we compare the results of the present study with those of the development of CCK-ir neurons (Meyer and Wahle, '88) we distinguish some cell types as characteristic for each peptide. For example, small neurons of layer I with intralaminar axons occur only in CCK-ir material, while pseudohorsetail cells are typical in the VIP/PHI-ir material. In contrast, other cell types are present in both the CCK- and VIP/PHI-ir material-for example, multipolar neurons of layer VI or the transient neurons with columnar 
dendritic fields. From a morphological point of view no difference can be found, so that the peptides could be colocalized in these neuronal types. However, the different chronology of the VIP/PHI-ir cell types which differentiate approximately 1 week later than the respective CCK-ir type (Fig. 17) indicates that cell types, although morphologically similar, might be biochemically different. In contrast, morphological similarities are not observed when CCK-ir or VIP/PHI-ir types are compared with NPY-ir cell types.

By morphological criteria most VIP/PHI-ir neuronal types resemble inhibitory short axon cells. Their similarity with CCK-ir neuronal types known to be GABA-ergic (Somogyi et al., '84) and, the fact that the termination pattern of VIP/PHI-ir basket cells resembles that of CCK-ir basket cells suggests that VIP/PHI and GABA could be colocalized in these types. For the rat this was recently reported by Papadopoulos et al. ('87). In the rat cortex, some VIP-ir neurons are colocalized with GABA, while others contain acetylcholine. An interesting question is to which cell types do the VIP/GABA neurons belong and how their synaptic connections appear? Most authors regard the bipolar cell as characteristic for the VIP-stained rodent and lagomorph cortex (Connor and Peters, '84; Morrison et al., '84; Magistretti and Morrison, '85; Loren et al., '76; McDonald et al., '82; Cajal-Aguieras et al., '86). Bipolar cells also display choline acetyltransferase (ChAT) immunoreactivity, indicating that acetylcholine is the main transmitter (Eckenstein and Baughman, '84). Other VIP-ir cell forms are present in the rat cortex, but have largely been neglected. Confusion exists about the terminal pattern of VIP-ir neurons. Leranth et al. ('84) and Peters et al. ('87) found symmetric synapses in rat and cat cortex and hippocampus which are considered as inhibitory (Eccles, '64). In contrast, also asymmetric VIP-ir synapses have been described which may derive from bipolar cells, which thus could be excitatory neurons (Peters and Kimmerer, '81; Connor and Peters, '84). This uncertainty may be solved by an unequivocal classification of VIP-ir neurons of the rat cortex on the basis of axonal patterns, to establish whether the synapses investigated derive from VIP-ir bipolar cells or from other cell types which may have a bipolar dendritic configuration, but a different axon and terminal pattern. It is possible that ChAT/VIP-ir bipolars form asymmetric synapses contacting dendritic spines (Connor and Peters, '84), while others, bipolar and nonbipolar VIP-ir types, may form symmetric ones contacting somata. Indeed, in a very recent study, evidence was presented that two forms of bipolar cells exist in rat cortex. One has axons forming symmetric synapses, also with pyramidal cell somata, the second one has axons forming asymmetric contacts (Peters and Harriman, '88).

A recent study on VIP-ir structures in the cat cortex described bipolar cells as a major cell type (Peters et al., '87). However, mainly "young adult cats" (without age specification) were analyzed so that the transient character of this cell type, the later-appearing basket cells, and the late postnatal reduction in cell density has not been recognized. Also, the question whether VIP/PHI small baskets of the cat cortex are GABA-ergic remains to be answered. The study of Demeulemeester et al. ('88) reveals no relation between VIP and GAD-ir structures in the cat visual cortex.

\section{Species differences}

Our findings argue for species differences between cat and rat cortex. In rodents and lagomorphs the bipolar cell form is characteristic for the adult cortex, while small basket neurons are definitive for the VIP/PHI-stained adult cat cortex, and bipolar cells are rare (also in Golgi material; Meyer, '83). Only during development is there a period in which the immature cat cortex is to a certain degree structurally reminiscent of the adult rat cortex, although the similarity is confined to the dendritic pattern of the transient bipolar cell type. This morphological difference between the two species is paralleled by a biochemical difference. The adult cat cortex contains only a very low number of putative cholinergic neurons (Stichel et al., '87) which, moreover, do not resemble bipolar cells of the rat cortex. Furthermore, a noncholinergic nature can be assumed also for our transient bipolar cells because a study of Stichel and Singer ('87) in the cat has not revealed ChAT-containing neurons of this striking morphology during the early postnatal period.

Some functional implications derive from these considerations. The "microcolumn" model (Magistretti et al., '84; Magistretti and Morrison, '85) concerning VIP action in the neocortex can be applied only to the rat cortex. The reason is that bipolar cells with dendrites extending from layer V/ VI to layer I (they represent the receptive element of the microcolumns) and axons which distribute within the microcolumns are absent in other species. Even the murine cortex only displays bipolar cells with shorter dendrites crossing one to at the most three layers, and which thus are similar to the bipolars of the cat cortex (Meyer et al., '83). If small cortical "hot-spots" with an increased protein phosphorylation and glycogen metabolism (Quik et al., '78; Magistretti et al., '81; Magistretti and Schoderet, '84) are generated in the adult cat, then a different structural basis must be assumed. The only VIP/PHI-ir cell type to come into question for this task are the basket cells, because they are common enough. Recently, Watling and Bristow ('86) reported that in the cortex the VIP-induced cAMP accumulation is enhanced via the $\mathrm{GABA}_{\mathrm{B}}$ receptor. So it is possible that VIP, stimulus-dependently cosecreted from a GABAergic terminal, enhances its effects via the metabotrophic (Costa et al., '87) receptors for the main transmitter which should be present in membrane sites postsynaptic to GABA-ergic terminals. The consequence is that specific visual information and metabolic signals are processed via the same neuronal circuits and synaptic pathways.

The transient bipolar cells of even the early postnatal kitten cortex might be ineffective in generating a columnar "hot-spot." They possess long receptive elements, but their axons reach only layers V and VI and the white matter, and do not project to superficial layers.

Finally, it should be mentioned that the visual cortex receives a VIP-ir projection originating from the intralaminar nuclei of the thalamus (Sugimoto et al., '85). These afferents end in layers I, III/IV border, and VI (Kaufman and Rosenquist, '85). It is possible that the sparse fibers observed in layer I of the adult animals are of extrinsic origin because they could not be traced back to an intrinsic component. In layer VI, afferents could not be distinguished from fibers of intrinsic origin, in that we did not observe axonal patterns different from the intrinsic ones described above. The VIP-ir afferents seem not to interfere with the analysis of VIP/PHI-ir intrinsic innervation: for example, no area differences are found between areas 17 and 18 , although area 18 receives by far more afferent fibers from intralaminar nuclei than area 17.

\section{SUMMARY}

The present study is part of a series of reports (Wahle and Meyer, '87a; Wahle et al., '87; Meyer and Wahle, '88) on the 
morphology and chronology of peptidergic neuronal types in the cat visual cortex. We would like to summarize the results of our classification during development in Figure 17. It is evident that the first postnatal month is a period of enormous structural plasticity in which various components of the innervation change and the pattern becomes completely reorganized within several days. Prominent transient cell types start to differentiate perinatally and are present more or less until the end of the first month. During that early period the whole range from prenatally differentiating "archaic" NPY-ir cell types of the first population, which are reminiscent of neurons of the reptilian cortical organization (Marin-Padilla, '71, '72), to the late postnatally differentiating CCK-ir basket cells can be identified. The various neuronal populations display different kinetics: the NPY-ir system is most dynamic with six transient cell types, while the CCK-ir structures appear more static, in that the adult pattern is the result of a sequential maturation of three persisting neuronal populations. The VIP/PHI-ir system occupies an intermediate position. The diagram further shows that peptidergic neuronal types of the same cortical layer mature at different times, for example, the NPY-ir basket cells of layer VI appear during the third postnatal week, while the CCK-ir multipolar neurons of layer VI are present already at $\mathrm{P} 0$. There seems to be no relationship between the time of birth and the time of differentiation of a neuron. A certain relationship, however, seems to exist between the time of the development of the neurons of a given type and the extent of their axon plexuses: The shorter or more local the axonal connection, the later it is to develop. First to differentiate are the peptidergic cells with long axonal connections; only the persisting marginal-zone-derived CCK-ir cells of layer I are an exception. Our classification scheme, based on immunohistochemistry and classical morphological criteria, has revealed several neuronal categories recognizable as an entity only by the biochemical marker. Several types and their specific connections, e.g., NPY-ir axonal loop cells, the VIP/PHI-ir pseudohorsetail cells, and the CCK-ir neuronal types with axons terminating in layer VI, have not previously been recognized by the Golgi method. Some of the CCK-ir types were also described by Freund et al. ('86).

Transient cell types apparently disappear by degeneration and cell death after a certain period which is characteristic for each types. During this period, the normal adult pattern differentiates. Our results did not reveal morphological transformation from one into another cell type. Signs of degeneration are also observed in neurons belonging to persisting types. This, together with the observation of a heterochronous maturation suggests that they may undergo a certain turnover (not encoded in the diagram). The turnover is especially prominent in neuronal types with long range projections most of which appear early postnatally. There seems to be no guarantee that the early-appearing individuals of persisting types survive into adulthood. They may die and become replaced by equivalent neurons which have started differentiation several days later.

The most prominent axonal projection patterns, indicated by arrows, are compared to each other in Figure 18. Axonal circuits of early appearing peptidergic neurons mainly involve layer I, layer VI, and the subplate. Subplatederived NPY-ir axonal loop cells which are GABA-ergic (Wahle et al., ' 87 ) could exert an inhibitory influence in superficial layers. Here they may interact with various components, for example, with the dendritic tufts of layer $V$

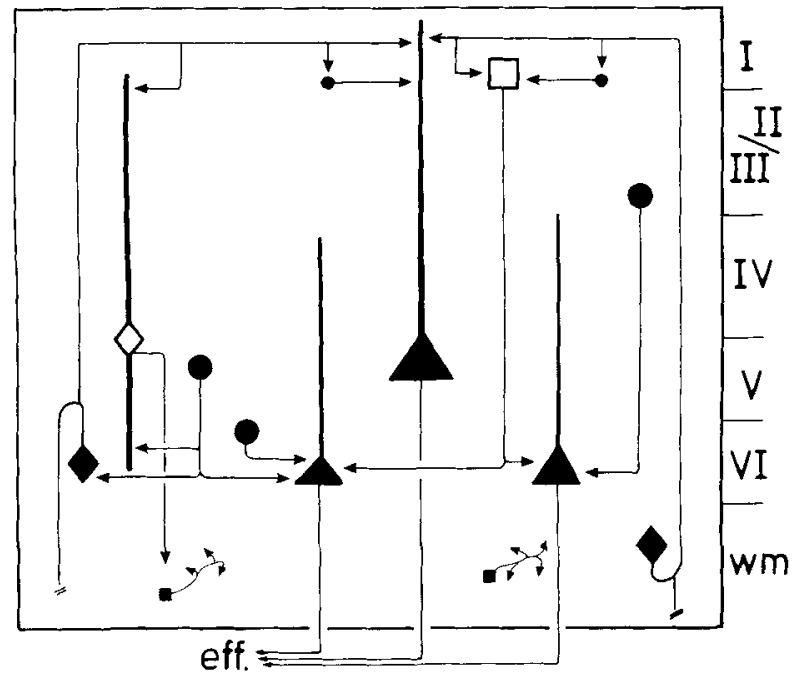

Fig. 18. Hypothetical circuits of peptidergic neuronal types in the cat striate cortex. The major axonal projection patterns axons tipped by arrows of neuronal types observed in the early postnatal cortex are summarized. eff., efferent axons; wm, white matter. Symbols encode the cell types: $\square$, VIP/PHI-ir pseudo-horsetail cells; 9 , CCK-ir neurons of layer I; $\diamond$, VIP/PHI-ir transient bipolar cells; $\mathrm{CCK}$-ir neurons of layers II/III/V/VI; $\Delta$, pyramidal cells of layers V/VI; $\bullet$, NPY-ir axonal loop cells; $\mathbf{\square}$, GAD-ir local basket cells of the white matter.

pyramidal cells, the CCK-ir short axon cells of layer I, the VIP/PHI-ir pseudohorsetail cells, or the long dendrites of transient bipolar cells. Inhibition and disinhibition via one or more than one synapse is possible. From the layer I information then is sent back to layer VI by the pseudohorsetail cells, and onto subplate neurons of the white matter by transient bipolar cells. This way the circuit would be closed. So far, nothing can be said about the physiological role of these projections, because we do not know whether GABA or excitatory main transmitters are present in pseudohorsetail cells and transient bipolar cells. Further complexity could be added the two pathways: VIP/PHI- and CCK-ir neurons of layers $I I / I I I, I V, V$ and $V I$ project into layer VI and could interact with persisting (pyramidal and nonpyramidal) and transient cell types (NPY-ir axonal loop cells, VIP/PHI-ir transient bipolar cells) of this layer; at least for the CCK-ir cells an inhibitory influence can be assumed, because CCK-ir neurons are GABA-ergic (Somogyi et al., '84; see discussion in Meyer and Wahle, '88). The long dendrites of transient bipolar cells collect information which arrives in all cortical layers and which then is transmitted onto subplate neurons, too. For example, during the peak of this projection many mature somatostatin-ir neurons are present in the upper subplate (Wahle, in preparation). They may represent a target for bipolar cell axons. Immunoelectronmicroscopy, however, should prove the synaptic nature of hypothetical wiring diagram circuits sketched in Figure 18 and outlined above.

The results and considerations presented in our studies refer only to the cat visual areas 17 and 18. It should be kept in mind that cell types, postnatal chronologies, and the adult innervation pattern may vary in other cortical areas and other species. Data obtained in the visual cortex should be generalized with caution. For example, the CCK-ir innervations differs between areas 17 and 18 (Meyer and Wahle, '88), and the VIP/PHI-ir bipolar cells are a good example for 
the morphological variability and the presence or absence of a cell type in different species.

\section{ACKNOWLEDGMENTS}

Our work was supported by the Max Planck Society, the Consejo Superior de Investigaciones Cientificas, and the DFG (Schwerpunkt Verhaltensontogenie). We thank Dr. J.M. Polak for providing us with the excellent antisera against VIP and PHI, and Drs. K. Albus, R. Ferres-Torres, H. Redies, P. Martin, and Claudia Sanides-Buchholtz for discussion.

\section{LITERATURE CITED}

Arimatsu, Y., J.R. Naegele, and C. Barnstable (1987) Molecular markers of neuronal subpopulations in layers 4,5 , and 6 of cat primary visual cortex. J. Neurosci. 7:1250-1263.

Bishop, A.E., J.M. Polak, Y. Yiangau, N.D. Christofides, and S.R. Bloom (1984) The distribution of VIP and PHI in porcine gut and their co-localization to a proportion of intrinsic ganglion cells. Peptides (Fayetteville) 5:255-259.

Boothe, R.G., W.T. Greenough, J.S. Lund, and K. Wrege (1979) A quantitative investigation of spine and dendrite development of neurons in the visual cortex (area 17) of macaca nemestrina monkeys. J. Comp. Neurol. $183: 473-490$.

Bradford, R.G., J.G. Parnavelas, and A.R. Liebermann (1977) Neurons in layer I of the developing occipital cortex of the rat. J. Comp. Neurol. 176:121-132

Cajal-Agüeras, S.R., P. Contamina, and L. Martinez-Millan (1986) The distribution of VIP-ir neurons in the visual cortex of adult rabbits and during postnatal development. Brain Res. 370:333-337.

Cavanagh, M.E., and J.G. Panavelas (1988) Development of somatostatin immunoreactive neurons in the rat occipital cortex: A combined immunocytochemical-autoradiographic study. J. Comp. Neurol, 268:1-12.

Christofides, N.D., Y. Yiangou, M.A. Blank, K. Tatemoto, J.M. Polak, and S.R. Bloom (1982a) Are peptide histidine isoleucine and vasoactive intes tinal polypeptide co-synthezised in the same pro-hormone? Lancet $2: 1398$.

Christofides, N.D., Y. Yiangou, G.P. McGregor, E. Aarons, P.L. Woodhams, K. Tatemoto, J.M. Polak, and S.R. Bloom (1982b) Distribution of PHI in the rat brain. Biomed. Res. 3:573, 574 .

Christofides, N.D., G.P. McGregor, P.L. Woodhams, Y. Yiangou, E. Aarons K. Tatemoto, and J.M. Polak (1983a) Ontogeny of PHI in the rat brain Brain Res. 264:359-361.

Christofides, N.D., Y. Yiangou, E. Aarons, G.-L. Ferri, K. Tatemoto, J.M Polak, and S.R. Bloom (1983b) Radioimmunoassay and intramural distribution of PHI-ir in the human intestine. Dig. Dis. Sci. 28:507-512.

Chun, J.J., M.J. Nakamura, and C.J. Shatz (1987) Transient cells of the developing mammalian telencephalon are peptide-immunoreactive neurons. Nature 325:617-620.

Chu-Wang, I.W., and R.W. Oppenheim (1977) Cell death of motoneurons in the chick embryo spinal cord. J. Comp. Neurol. 177:35-58

Connor, J.R., and A. Peters (1984) Vasoactive intestinal polypeptide-immunoreactive neurons in the rat visual cortex. Neuroscience 12:127-1044.

Costa, E., A. Berkovich, and A. Guidotti (1987) The regulation of GABA-ergic receptors by a novel family of endogenous neuropeptides. Life Sci. 41:799-803.

Cowan, W.M. (1970) Anterograde and retrograde transneuronal degeneration in the central and peripheral nervous system. In W.J.H. Nauta and S.O.E. Ebbesson (eds): Contemporary Research Methods in Neuroanatomy. New York: Springer, pp. 217-251.

Cowan, M.W. (1973) Neuronal death as a regulative mechanism in control of cell number in the nervous system. In $\mathrm{M}$. Rockstein (ed): Development and Aging of the Nervous System. New York: Academic Press, pp. 19 41.

Cowan, M.W., J.W. Fawcett, D.D.M. O'Leary, and B.B. Stanfield (1984) Regressive events in neurogenesis. Science 225:1258-1265.

Cragg, B.G. (1975) The development of synapses in the visual system of the cat. J. Comp. Neurol. 16:147-166.

Demeulemeester, H., F. Vandesande, G.A. Orban, S. Brandon, and J.J. Vanderhagen (1988) Heterogeneity of GABA-ergic cells in cat visual cortex. $J$ Neurosci. 8:988-1000.
Eccles, J.C. (1964) The Physiology of Synapses. Springer: Berlin.

Eckenstein, F., and R.W. Baughman (1984) Two types of cholinergic innervation in cortex, one co-localized with vasoactive intestinal polypeptide. Nature 309:152-155.

Emson, P.C., R.F.T. Gilbert, I. Loren, J. Fahrenkrug, F. Sundler, and D. Schaffalitzky de Muckadell (1979) Development of VIP-containing neurons in the rat brain. Brain Res. 177:437-444.

Fahrenkrug, J. (1985) Evidence for common precursor but differential processing of VIP and PHI in VIP-producing tumors. Peptides (Fayetteville) 6:357 -361.

Fahrenkrug, J., and J.H. Pedersen (1986) Co-secretion of peptide histidine methionine (PHM) and vasoactive intestinal polypeptide in patients with VIP-producing tumors. Peptides (Fayetteville) 7:717-721.

Fahrenkrug, J., T. Bek, J.M. Lundberg, and T. Hökfelt (1985) VIP and P.HI in cat neurons: $\mathrm{Co}$-localization but variable tissue content possible due to differential processing. Regul. Pept. 12:21-34.

Feldman, M.L., and C. Dowd (1975) Loss of dendritic spines in aging cerebral cortex. Anat. Embryol. (Berl.) 148:279-301.

Finlay, B.L., K.C. Wikler, and D.R. Sengelaub (1987) Regressive events in brain development and scenarios for vertebrate evolution. Brain Behav. Evol. 30:102-117.

Freund, T.F., Z. Magloczky, I. Soltesz, and P. Somogyi (1986) Synaptic connections, axonal and dendritic patterns of neurons immunoreactive for cholecystokinin in the visual cortex of the cat. Neuroscience 19:11331159.

Glücksmann, A. (1950) Cell death in normal vertebrate ontogenesis. Biol. Rev. 26:59-86.

Goodman, C.S., C.M. Bate, and N.C. Spitzer (1981) Embryonic development of identified neurons. Origin and transformation of the H-cell. J. Neurosci. 11:94-102

Hares, K.A.R. and G.A. Foster (1988) Immunohistochemical analysis of the ontogeny of peptide histidine isoleucine-immunoreactive (PHI) neurons in the pre- and postnatal rat brain. Dev. Brain Res. 40:99-112.

Hamburger, V., and R.W. Oppenheim (1982) Naturally occuring neuronal death in vertebrates. Neurosci. Comment 1:39-55.

Heimer, L., and R. Kalil (1978) Rapid transneuronal degeneration and death of cortical neurons following removal of the olfactory bulb in adult rats. J. Comp. Neurol. 178:559-609.

Heumann, D., and G. Leuba (1983) Neuronal death in the development and aging of the cerebral cortex of the mouse. Neuropathol. Appl. Neurobiol. 9:297-311.

Innocenti, G.M., S. Clarke, and R. Kraftsik (1986) Interchange of callosal and association projections in the developing visual system. J. Neurosci. $6: 1384-1400$.

Kaufman, E.F., and A.C. Rosenquist (1985) Efferent projections of the thalamic intralaminar nuclei in the cat brain. Brain. Res. 335:257-279.

Kenny, J. (1986) Cell surface peptidases are neither peptide- nor organ-specific. Trends Biochem. Sci. 11:40-42.

Kostovic, I, and P. Rakic (1980) Cytology and time of origin of interstitial neurons in the white matter in infant and adult human and monkey telencephalon. J. Neurocytol. 9:219-242.

Kuljis, R.O., and H.J. Karten (1986) Substance P-containing ganglion cells become progressively less detectable during retinotectal development in the frog Rana pipiens. Proc. Natl. Acad. Sci. U.S.A. 83:5736-5740.

Leranth, C., M. Frotscher, T. Tömböl, and M. Palkovits (1984) Ultrastructure and synaptic connections of vasoactive intestinal polypeptide-like immunoreactive non-pyramidal neurons and axon terminals in rat hippocampus. Neuroscience 12.531-542.

Lieberman, A.R. (1971) The axon reaction: A review of the principal features of perikaryal response to axon injury. Int. Rev. Neurobiol. 14:40-124.

Linder, S., T. Barkhem, A. Norberg, H. Persson, M. Schalling, T. Hökfelt and G. Magnusson (1987) Structure and expression of the gene encoding: the vasoactive intestinal polypeptide precursor. Proc. Natl. Acad. Sci. U.S.A. 84:605-609.

Loren, I., P.C. Emson, J. Fahrenkrug, A. Björklund, J. Alumets, R. Hakanson, and F. Sundler (1976) Distribution of vasoactive intestinal polypeptide in the rat and mouse brain. Neuroscience 4:1953-1976.

Lund, J.S., R.G. Boothe, and R.D. Lund (1977) Development of neurons in the visual cortex area 17 of the monkey (Macaca nemestrina): A Golgi study from fetal day 127 to postnatal maturity. J. Comp. Neurol. 176:149188.

Luskin, M.B., and C.J. Shatz (1985a) Studies on the earliest generated cells of the cat visual cortex: Cogeneration of subplate and marginal zones. J. Neurosci. 5:1062-1075.

Luskin, M.B., and C.J. Shatz (1985b) Neurogenesis of the cat's primary visual 
cortex. J. Comp. Neurol. 242:611-631.

Magistretti, P.J., and M. Schorderet (1984) VIP and noradrenaline act synergistically to increase cylic AMP in cerebral cortex. Nature 308:280-282.

Magistretti, P.J., and J.H. Morrison (1985) VIP neurons is the neocortex. Trends Neurosei. 8:7,8.

Magistretti, P.J., J.H. Morrison, W.J. Shoemaker, V. Spain, and F.E. Bloom (1981) Vasoactive intestinal polypeptide induces glycogenolysis in mouse cortical slices: A possible regulatory mechanism for the local control of energy metabolism. Proc. Natl. Acad. Sci. U.S.A. 78:6635-6639.

Magistretti, P.J., J.H. Morrison, W.J. Shoemaker, and F.E. Bloom (1984) Morphological and functional correlates of VIP neurons in the cerebral cortex. Peptides (Fayetteville) 5:213-218.

Marin-Padilla, M. (1971) Early prenatal ontogenesis of the cerebral cortex (neocortex) of the cat (Felis Domestica). A Golgi study. I. The primordia neocortical organization. Z. Anat. Entwickl.-Gesch. 134:117-145.

Marin-Padilla, M. (1972) Prenatal ontogenetic history of the principal neurons of the neocortex of the cat. A Golgi study. II. Development of differences and their significances. Z. Anat. Entwickl.-Gesch. 136:125-142.

Martin, D.P., R.E. Schmidt, P.S. Distefano, O.H. Lowri, J.C. Carter and E.M Johnson (1988) Inhibitors of protein synthesis factor deprivation and RNA synthesis prevents neuronal death caused by nerve growth factor deprivation. J. Cell Biol. 106:829-844.

Matthews, M.A. (1973) Death of the central neuron. J. Neurocytol. 2:265288.

McDonald, J.K., J.G. Parnavelas, A.N. Karamanlidis, and N. Brecha (1982) The morphology and distribution of peptide-containing neurons in the adult and developing visual cortex of the rat. II. Vasoactive intestinal polypeptide. J. Neurocytol. 11:825-837.

Meyer, G. (1983) Axonal patterns and topography of short axon neurones in visual areas 17, 18 and 19 of the cat. J. Comp. Neurol. 220:405-438.

Meyer, G. (1987) Forms and spatial arrangements of neurons in the primary motor cortex of man. J. Comp. Neurol. 262:402-429.

Meyer, G., and R. Ferres-Torres (1984) Postnatal maturation of nonpyramidal neurones in the visual cortex of the cat. J. Comp. Neurol. 228:226244.

Meyer, G., and P. Wahle (1988) The early postnatal development of CCK-ir structures in the visual cortex of the cat. J. Comp. Neurol., 276:360-380.

Meyer, G., A. Losada-Cabrera, and R. Ferres-Torres (1983) Axonal patterns of interneurons in area 17 of cats and mice. Neurosci. Lett. [Suppl.] $14: 247$.

Morrison, J.H., P.J. Magistretti, R. Benoit, and F.E. Bloom (1984) The distribution and morphological characteristics of the intracortical VIP-positive cell: An immunohistochemical analysis. Brain Res. 292:269-282.

Naegele, J.R., Y. Arimatsu, P. Schwartz, and C.J. Barnstable (1988) Selective staining of a subset of GABA-ergic neurons in cat visual cortex by monoclonal antibody VC1.1. J. Neurosci. 8:78-89.

Obata-Tsuto, H.L., H. Okamura, T. Tsuto, H. Terubayashi, K. Fukui, N Yanaihara, and Y. Ibata (1983) Distribution of the VIP-like immunoreactive neurons in the cat central nervous system. Brain Res. Bull. 10:653660.

Okamura, H., S. Murakami, K. Fukui, K. Uda, K. Kawamoto, S. Kawashima, N. Yanaihara, and Y. Ibata (1986) Vasoactive intestinal polypeptide and peptide histidine isoleucine amide-like immunoreactivity colocalize with vasopressin in the canine hypothalamo-hypophyseal neuronal system. Neurosci. Lett. 69:227-232

O'Kusky, J.R. (1985) Synapse elimination in the developing visual cortex: A morphometric analysis in normal and dark-reared cats. Dev. Brain Res. 22:81-91.

O'Kusky, J.R., and M. Colonnier (1982) Postnatal changes in the number of neurons and synapses in the visual cortex (area 17) of the macaque monkey: A stereological analysis in normal and monocularly deprived animals. J. Comp. Neurol. 210:291-306.

O'Leary, D.D.M., and B.B. Stanfield (1985) Occipital cortical neurons with transient pyramidal tract axons extend and maintain collaterals to subcortical but not intracortical targets. Brain Res. 336:326-333.

Oppenheim, R.W. (1985) Naturally occurring cell death during neural development. Trends Neurosci. 8:489-495.

Papadopoulos, G.C., J.G. Parnavelas, and M.E. Cavanaugh (1987) Extensive coexistence of neuropeptides in the rat visual cortex. Brain Res. 420:9599.

Parnavelas, J.G., R. Luder, E.J. Mounty, and A.R. Lieberman (1978) The development of non-pyramidal neurons in the visual cortex of the rat. Anat. Embryol. (Berl.) 155:1-14.

Peters, A., and L.M. Kimmerer (1981) Bipolar cells in the rat visual cortex: A combined Golgi-electronmicroscope study. J. Neurocytol. 10:921-946.
Peters, A., and K. Harriman (1988) The enigmatic bipolar cell of the rat visual cortex. J. Comp. Neurol. 267;409-433.

Peters, A., S.L. Palay, and H. Webster (1974) The Fine Structure of the Nervous System. Philadelphia: W.B. Sounders Company.

Peters, A., D.L. Meinecke, and A. Karamanlidis (1987) Vasoactive intestinal polypeptide immunoreactive neurons in the primary visual cortex of the cat. J. Neurocytol. 16:23-38.

Purpura, D.P., M.W. Carmichael, and E.M. Housepian (1960) Physiological and anatomical studies on the development of superficial axodendritic synaptic pathways in neocortex. Exp. Neurol. 2:324-347.

Quik, M., L.L. Iversen, and S.R. Bloom (1978) Effect of vasoactive intestinal polypeptide and other peptides on cAMP accumulation in rat brain. Biochem. Pharmacol. 27:2209-2213.

Rakic, P. (1972) Mode of cell migration to the superficial layers of fetal monkey neocortex. J. Comp. Neurol. 145:61-84.

Romijn, H.J., F. VanHuizen, and S.P. Wolters (1984) Towards an improved serum-free, chemically defined medium for long term culturing of cerebral cortex tissue. Neurosci. Biobehav. Rev. 8:301-334.

Said, S.I. (1984) Vasoactive intestinal polypeptide (VIP): Current status. Peptides (Fayetteville) 5:143-150.

Schwartz, J.C. (1983) Metabolism, and the inactivating neuropeptidase concept. Trends Neurosci. 6:45-48.

Seeds, N.W., R.L. Hawkins, S. Verrall, and A. Krystosek (1987) Extracellular proteases and their inhibitors influence neuronal development. Neurosci. Abstr. [Suppl.] 22:283 (Abstract).

Sengelaub, D.R., R.P. Dolan, and B.L. Finlay (1986) Cell generation, death and retinal growth in development of the hamster retinal ganglion cell layer. J. Comp. Neurol. 246:527-542.

Shatz, C.J., and M.B. Luskin (1986) The relationship between the geniculocortical afferents and their cortical target cells during development of the cat's primary visual cortex. J. Neurosci. 6:3655-3668.

Somogyi, P., A.J. Hodgson, A.D. Smith, M.C. Nunci, M. Gracia, A. Gorio, and J.-Y. Wu (1984) Different populations of GABA-ergic neurons in the visual cortex and the hippocampus of the cat contain somatostatin or cholecystokinin-immunoreactive material. J. Neurosci. 4:2590-2603.

Stichel, C.C., and W. Singer (1987) Quantitative analysis of the choline acetyltransferase-immunoreactive axonal network in the cat primary visual cortex: II. Pre- and postnatal development. J. Comp. Neurol. 258:99111.

Stichel, C.C., A. Dolabela de Lima, and W. Singer (1987) A search for choline acetyltransferase-like immunoreactivity in neurons of the cat striate cortex. Brain Res. 405:395-399.

Strittmatter, S.M., D.R. Lynch, and S.H. Snyder (1986) Differential ontogeny of rat brain peptidases: prenatal expression of enkephalin convertase and postnatal development of angiotensin converting enzyme. Dev. Brain Res. 29:207-215.

Sugimoto, T., K. Itoh, Y. Yasui, T. Kaneko, and N. Mizuno (1985) Coexistence of neuropeptides in projection neurons of the thalamus of the cat. Brain Res. 347:381-384.

Szentagothai, J. (1973) Synaptology of the visual cortex. In R. Jung (ed): Handbook of Sensory Physiology, Vol. VIII/3. Heidelberg: Springer, p267-348.

Tatemoto, K. (1984) PHI - a new brain gut peptide. Peptides (Fayetteville) 5:151-154.

Tatemoto, K., and V. Mutt (1981) Isolation and characterization of the intestinal peptide porcine PHI (PHI-27), a new member of the glucagonsecretin family. Proc. Natl. Acad. Sci. U.S.A. 78:663-667.

Thoenen, H., Y.A. Barde, A.M. Davies, and J.E. Johnson (1987) Neurotrophic factors and neuronal death. In Selective Neuronal Death. Chichester: Wiley (Ciba Foundation Symposium 126), pp. 82-95.

Valverde, F., and M.V. Facal-Valverde (1987) Transitory populations of cells in the temporal cortex of the kitten. Dev. Brain Res. 32:283-288.

Valverde, F., and M.V. Facal-Valverde (1988) Postnatal development of Interstital (Subplate) cells in the white matter of the temporal cortex of kittens: A correlated Golgi and Electronmicroscopic study. J. Comp. Neurol. $269: 168-192$.

Wahle, P. (1987) Morphologie und Projektionsverhalten peptiderger Neuronen im Zentralnervensystem der Katze. Eine immunhistochemische Studie über die postnatale Entwicklung peptiderger Neuronensysteme im visuellen Cortex der Katze. Thesis, University of Göttingen.

Wahle, P., and G. Meyer (1987a) Morphology and postnatal changes of transient NPY-ir neuronal populations during early postnatal development of the cat visual cortex. J. Comp. Neurol. 261:165-195.

Wahle, P., and G. Meyer (1987b) The early postnatal ontogenesis of VIP/PHI and CCK-immunoreactive structures in the cat visual cortex. Soc. Nec- 
rosci. Abstr. 13:1115.

Wahle, P., G. Meyer, J.-Y. Wu, and K. Albus (1987) Morphology and axon terminal pattern of GAD-ir cell types in the white matter of the cat occipital cortex during early postnatal development. Dev. Brain Res. 36:5361.

Wahle, P. C. Sanides-Buchholtz, and K. Albus (1988) Postnatal development of Substance P-ir structures in the cat visual cortex: Neurons with ascending axons become less and less detectable. Soc. Neurosci. Abstr. 14:701.

Watling, K.J., and D.R. Bristow (1986) $G A B A_{B}$ receptor-mediated enhancement of vasoactive intestinal polypeptide stimulated cAMP production in slices of rat cerebral cortex. J. Neurochem. 46:1755-1762.

Winfield, D.A. (1981) The postnatal development of synapses in the visual cortex of the cat and the effects of eyelid closure. Brain Res. 260:166-171.

Wolff, J.R., H. Boettcher, T. Zetzche, W.H. Oertel, and B.H. Chronwall (1984) Development of GABA-ergic neurons in the rat visual cortex as identified by glutamate decarboxylase-like immunoreactivity. Neurosci. Lett. 47:207-212.

Wong-Riley, M. (1979) Changes in the visual system of monocularly sutured or enucleated cats demonstrated with cytochrome oxidase histochemistry. Brain Res. 171:11-28. 